\title{
International Value-Added Linkages in Development Accounting*
}

\author{
Alejandro Cuñat ${ }^{\dagger} \quad$ Robert Zymek ${ }^{\ddagger}$
}

July 2017

\begin{abstract}
We generalise the traditional development-accounting framework to an openeconomy setting. In addition to factor endowments and productivity, relative factor costs emerge as a source of real-income variation across countries. These are determined by bilateral trade frictions (which underpin the patterns of "international value-added linkages") and the global distribution of factor endowments and final expenditures. We use information on endowments, trade balances and value-added trade to back out the relative factor costs of 40 major economies in a theory-consistent manner. This reduces the variation in "residual" TFP required to explain the observed per-capita income differences by more than one half.
\end{abstract}

JEL Classification codes: E01, F15, F40, F62, F63

Keywords: world input-output, development accounting, transfer effect

*We are grateful to Pol Antràs, Rudolfs Bems, Harald Fadinger, Gabriel Felbermayr, Jan Grobovšek, Tim Kehoe, Mariko Klasing, Nan Li, Marc Melitz, Petros Milionis, Ralph Ossa, Giacomo Ponzetto, Stephen Redding, Jaume Ventura and seminar participants at CREI, the IMF, Vienna, Groningen, the ifo Institute, Edinburgh, Heriot Watt, Trento, Valencia, the 2016 German Christmas Meeting, the 2017 RES Conference, and the 2017 SED Conference for helpful comments and suggestions. We would especially like to thank Rob Feenstra for a very instructive discussion. Cuñat gratefully acknowledges the hospitality of CREI while this paper was conceived, and financial support from Spain's CICYT (ECO2011-29050).

${ }^{\dagger}$ Department of Economics, University of Vienna and CESifo, Oskar Morgenstern Platz 1, Vienna 1090, Austria; alejandro.cunat@univie.ac.at.

$\ddagger$ School of Economics, University of Edinburgh and CESifo, 31 Buccleuch Place, Edinburgh, EH8 9JT, United Kingdom; robert.zymek@ed.ac.uk. 


\section{Introduction}

What explains the large differences in per-capita incomes across countries? Over the last two decades, the rise of development accounting has subjected theorising about this age-old economic question to the discipline of empirical evidence. Developmentaccounting studies provide a quantitative assessment of the share of international income differences which can be attributed to differences in measurable production factors (such as endowments of physical and human capital) and attribute the remainder to unobservable differences in "total factor productivity" (TFP). A key finding of this literature is that TFP differences appear to explain by far the largest portion of the variation in incomes across countries. ${ }^{1}$ This is sobering: since TFP is measured indirectly, as the residual determinant of incomes once the contribution of all measurable economic aggregates has been accounted for, it captures all drivers of income differences which elude quantification. It thus represents a "measure of ignorance" (Abramovitz, 1956) about what makes some countries rich, and others poor.

Most exercises in development accounting proceed under the, implicit or explicit, assumption that countries are closed. ${ }^{2}$ Consequently, they are silent on how differences in countries' international-trade linkages contribute to shaping the observed distribution of per-capita incomes. This simplification is made for analytical convenience, but seems unsatisfactory from an empirical standpoint: numerous econometric studies have documented a relationship between the extent and pattern of regions' access to other markets, and their income levels. ${ }^{3}$ In this paper, we generalise the standard development-accounting framework to a setting in which countries are open to trade. We show that recent data on countries' final use of foreign value added - their international value-added linkages - can be used to discipline the traderelated portion of our generalised development-accounting equation. For a sample of 40 major economies, the generalised equation doubles the share of per-capita income differences which can be explained with data, and cuts the implied cross-country variation in unobserved TFP by more than one half.

Our paper departs from theoretical expressions for countries' incomes and valueadded trade patterns which can be derived from standard quantitative trade models. We show that in such models, a country's real per-worker GDP evaluated at consumer prices (the conventional measure of welfare in cross-country comparisons) depends not

\footnotetext{
${ }^{1}$ See Klenow and Rodríguez-Clare (1997), Hall and Jones (1999), Caselli (2005), Hsieh and Klenow (2010), and Jones (2015).

${ }^{2}$ See Jones (2015) and Malmberg (2016) for some recent examples.

${ }^{3}$ For example, Redding and Venables (2004) document that the geography of access to markets and sources of supply is a key predictor of per-capita incomes across countries. More generally, empirical economic geography has recognised differences in "market potential" - a region's access to other significant markets - as a source of regional income variation since Harris (1954).
} 
only on the country's domestic production factors and productivity, but also on its factor cost relative to the weighted factor costs of its goods suppliers. This is intuitive. A country's own factor cost represents the price of its output in global markets, while the factor costs of its suppliers shape the country's consumer price level. Variation in the relative magnitude of own factor costs to source factor costs thus emerges as a determinant of real income differences in an integrated world. Such variation, in turn, reflects differences in countries' terms of trade and bilateral trade frictions.

The new "relative factor cost" term comprehensively encapsulates the influence of countries' international linkages on their real GDP. For given factor endowments, countries facing stronger demand from abroad for their value added - because they supply markets which account for a large share of global spending - will have relatively high factor costs. For given factor costs, countries which are able to source more value added from low-cost economies will have relatively low consumer prices. Both result in relatively higher real incomes. Calibrating our model equations to match observed patterns of international trade in value added, it is possible to gauge how the "relative factor cost" term varies across countries. To do so, we combine standard data on the factor endowments of 40 major economies with information on their international value-added linkages and trade balances from the World Input Output Database (WIOD). We then perform open-economy development accounting under different assumptions about a new key parameter which needs to be specified for this purpose - the trade elasticity.

In our benchmark year, a traditional development-accounting exercise (disregarding international linkages) explains only $25 \%$ of international income variation as a result of differences in measurable production factors. The remainder must be attributed to variation in unobserved TFP (28\%) and the covariance between TFP and production factors (47\%). By contrast, our augmented framework explains at least $50 \%$ of the variation as a result of differences in measurable production factors and relative factor costs, and cuts the implied cross-country variation in unobserved TFP by more than one half. ${ }^{4}$ Therefore, our open-economy generalisation of the standard development accounting framework substantially reduces the need to rely on TFP differences in explaining observed differences in living standards across countries. Having established the robustness of this finding, we illustrate the role of trade imbalances and trade costs in determining real income levels through a number of counterfactuals. These counterfactuals allow us to highlight that our findings are consistent with earlier quantitative explorations of the effect of trade on incomes, but extend them along a novel dimension. ${ }^{5}$

\footnotetext{
${ }^{4}$ WIOD data required to calculate international-value added linkages is available for the period 1995-2011. We choose 2006 as the benchmark year for our study, but obtain quantitatively similar results for other years from that period.

${ }^{5}$ Notably, Eaton and Kortum (2002) and Waugh (2010) use models similar to ours to ask how
} 
Our paper contributes to the literature on development accounting, popularised by the seminal work of Hall and Jones (1999). Caselli (2005, 2015) offers extensive reviews of this literature, discussing methodologies and data sources in depth. As described above, by focusing exclusively on countries' own production factors, most conventional development-accounting exercises ignore the potential effects of international linkages on the incomes of countries. Here, we show how models belonging to a popular class of quantitative trade theories can be used to generalise traditional development-accounting frameworks for use in a setting of open economies. ${ }^{6}$ These models allow for country-pair-specific international linkages through which a country can utilise the value added generated in different countries in varying proportions in its own final production. We discipline them using novel data on countries' international input-output linkages from the WIOD.

The exercise we perform is related with Feenstra et al. (2009, 2015). These papers emphasise that real GDP evaluated at consumer prices may depart from an open economy's real productive potential because, with international trade, the same good may feature to different extents in a country's consumption and production baskets. ${ }^{7}$ They construct a new output-side deflator for GDP based on the traditional expenditure-side deflator and micro data on the unit values of countries' exports and imports. Recognising that development accounting ought to allow for differences in the "gap" between expenditure- and output-side real GDP across countries, Feenstra et al. (2015) use it to augment the standard development-accounting equation. We show that their "gap" is related to, but captures only part of, the "relative factor cost" term which exactly represents the gap between an open economy's productive potential and consumption possibilities in standard trade models. Therefore, the variation in relative factor costs which we measure in this paper contains additional information about the origins of income differences among open economies.

The use of data from input-output tables to tackle questions in development and macroeconomics has recently experienced a revival. There are now a number of studies which trace differences in countries' per-capita incomes to differences in their sectoral

counterfactual configurations of international trade costs would impact countries' incomes. These papers focus on quantifying the gains from trade, and their contribution to the world income distribution. By contrast, we quantify differences in countries' terms of trade and bilateral trade determinants on the basis of observed trade and factor-endowment data. We then show that these data-implied differences can help to explain cross-country income variation. Our approach implies a distinct counterfactual thought experiment: how much more similar would countries' incomes be if all countries faced the same terms of trade and bilateral trade determinants?

${ }^{6}$ Several studies explore the factor bias of technology in both closed- and open-economy settings. Caselli and Coleman (2006) calibrate the skill bias of technology by combining a closed-economy aggregate production function with data on output, factor inputs and factor prices. Trefler (1993), Fadinger (2011), and Morrow and Trefler (2014) estimate factor-augmenting productivities which reconcile versions of the Heckscher-Ohlin-Vanek model with the observed factor content of trade. We are instead concerned with overall productivity and the extent to which it varies across countries.

${ }^{7}$ In a similar vein, Kehoe and Ruhl (2008) highlight that relative price changes may cause measures of countries' real consumption possibilities and real production capacity to diverge. 
structure using national input-output tables. ${ }^{8}$ Our use of international input-output tables places the present paper in a flourishing literature in the realm of international macroeconomics using this new data source to trace international trade in valueadded. ${ }^{9}$ Among others, Bems et al. (2011), Bems (2014), Johnson (2014) and Duval et al. (2015) have recently emphasised that distinguishing international trade in value added from its gross counterpart is necessary for understanding short-run fluctuations in incomes and business cycle synchronisation across countries. Our findings add to this literature by highlighting that the patterns of international value-added linkages also have a role to play in explaining differences in the level of per-capita incomes.

The remainder of this paper is structured as follows. Section 2 presents the theoretical model that serves as the basis for our open-economy development accounting exercise. Section 3 describes our data sources and calibration strategy, and details the main results of our analysis. Section 4 motivates and carries out our counterfactual experiments. Section 5 offers a brief summary and concluding remarks.

\section{Model}

\subsection{Preferences, Technologies and Market Structure}

There are many countries, denoted by $n=1, \ldots, N$. Each country produces a unique good. The representative consumer in $n$ assembles goods to maximise aggregate consumption,

$$
C_{n}=A_{n}\left[\sum_{n^{\prime}=1}^{N} \omega_{n^{\prime} n}^{\frac{1}{\sigma}} c_{n^{\prime} n}^{\frac{\sigma-1}{\sigma}}\right]^{\frac{\sigma}{\sigma-1}}
$$

where $\sigma \geq 1, \omega_{n^{\prime} n} \geq 0 ; c_{n^{\prime} n}$ represents consumption in $n$ of the good produced by $n^{\prime}$; and $A_{n}$ is a country-specific productivity term. In the following, $A_{n}$ will play the role of the TFP residual in development accounting.

Countries receive income from their endowments of two production factors physical capital, $K_{n}$, and labour, $L_{n}$ - as well as from possible net transfers from

\footnotetext{
${ }^{8}$ This research agenda was initiated by Jones (2011), who shows that intermediate-input linkages amplify the effects of distortions in the allocation of resources, causing differences in measurements of aggregate TFP at the country level. Fadinger et al. (2015) provide evidence that part of the income differences between rich and poor countries can be attributed to systematic differences in the structure of their input-output matrices. Grobovšek (2015) employs a closed-economy development accounting framework and highlights that low per-capita incomes appear to be related to low levels of productivity in intermediate-input production. In a recent paper, Caliendo et al. (2017) use WIOD data to identify trade distortions and TFPs at the country-sector level across 40 economies.

${ }^{9}$ Kose and Yi (2001) and Yi $(2003,2010)$ were among the first to exploit the distinction between international trade in "gross" or "value-added" terms in the analysis of aggregate phenomena such as the growth of world trade and the international synchronisation of business cycles.
} 
abroad, $T_{n}$. Hence, the representative agent in $n$ maximises (1) subject to

$$
\sum_{n^{\prime}=1}^{N} p_{n^{\prime} n} c_{n^{\prime} n} \leq r_{n} K_{n}+w_{n} L_{n}+T_{n}
$$

where $p_{n^{\prime} n}$ is the price of the country- $n^{\prime}$ good in $n, r_{n}$ and $w_{n}$ respectively denote the returns to capital and labor, and $\sum_{n} T_{n}=0 .{ }^{10}$

Country $n$ produces its good using the production technology

$$
Q_{n}=Z_{n} K_{n}^{\alpha}\left(h_{n} L_{n}\right)^{1-\alpha}
$$

where $K_{n}$ and $L_{n}$ represent capital and labour used to produce the country- $n$ good; $h_{n}$ represents labour productivity in country $n$; and $\alpha \in(0,1)$. The shifter $Z_{n}$ describes the overall efficiency of good- $n$ production.

Goods and factor markets are perfectly competitive, but international trade is subject to iceberg transport costs: $\tau_{n^{\prime} n} \geq 1$ units of an input must be shipped from country $n^{\prime}$ for one unit to arrive in country $n$. Production factors can move freely between activities within countries, but cannot move across borders.

The Armington model outlined in this section has the benefit of simplicity. However, it makes two stark assumptions which may appear to limit its use in the quantitative analysis of international trade and incomes. First, by assuming that each country produces a unique good, it treats specialisation patterns in international trade as exogenous. Second, equations (1) and (3) imply that countries in the model trade directly in value added: a purchase of goods by country $n$ from country $n^{\prime}$ implies the use of country- $n^{\prime}$ factor services of equal value. This implies that trade along the production chain - whereby some countries supply intermediate inputs used in other countries' exports - is ruled out by assumption.

In Appendix A.1 we show that, for our purposes, the Armington model presented here can be interpreted as a short-cut representation of the popular quantitative trade model of Eaton and Kortum (2002). In that model, all countries can produce all goods, and countries optimally source goods from their lowest-cost suppliers. It also allows for an international input-output structure. Nevertheless, we show that the Eaton-Kortum model implies expressions for value-added trade flows and countries' incomes which are isomorphic to those derived in (7)-(9) below. For our developmentaccounting exercise it is thus immaterial whether we think of these expressions as arising from the microfoundations of the simple model described above, or the richer model sketched in the appendix.

\footnotetext{
${ }^{10}$ Following Dornbusch et al. (1977), we use exogenous income transfers to allow for trade imbalances in a static model.
} 


\subsection{Equilibrium}

We define country- $n$ factor costs in equilibrium as

$$
f_{n} \equiv \frac{1}{h_{n}^{1-\alpha}}\left(\frac{r_{n}}{\alpha}\right)^{\alpha}\left(\frac{w_{n}}{1-\alpha}\right)^{1-\alpha} .
$$

The price for country $n$ of a unit of country- $n^{\prime}$ good is then

$$
p_{n^{\prime} n}=\frac{\tau_{n^{\prime} n} f_{n^{\prime}}}{Z_{n^{\prime}}}
$$

It is straightforward to show that this implies

$$
P_{n} \equiv \frac{1}{A_{n}}\left(\sum_{n^{\prime}=1}^{N} \omega_{n^{\prime} n} p_{n^{\prime} n}^{1-\sigma}\right)^{\frac{1}{1-\sigma}}=\frac{1}{A_{n}}\left(\sum_{n^{\prime}=1}^{N} \gamma_{n^{\prime} n} f_{n^{\prime}}^{-\theta}\right)^{-\frac{1}{\theta}}
$$

where $P_{n}$ is the cost of one unit of final consumption in country $n$, and we define $\theta \equiv \sigma-1$ and $\gamma_{n^{\prime} n} \equiv \omega_{n^{\prime} n}\left(Z_{n^{\prime}} / \tau_{n^{\prime} n}\right)^{\theta}$. From this definition, $\gamma_{n^{\prime} n}$ captures all possible determinants of the relative importance of country- $n^{\prime}$ imports in the final expenditure of country $n$ - preferences, technology and bilateral trade costs: it depends positively on the taste of country $n$ for the output of country $n^{\prime}$, governed by $\omega_{n^{\prime} n}$; positively on the exporting country's productivity, $Z_{n^{\prime}}$; and negatively on the magnitude of the trade barriers between the two countries, $\tau_{n^{\prime} n}$. We label $\left\{\gamma_{n^{\prime} n}\right\}_{n^{\prime}, n}$ as the matrix of bilateral trade determinants, and treat these as parameters in our calibration below.

A simple application of Shephard's Lemma yields

$$
v_{n^{\prime} n}=\frac{\gamma_{n^{\prime} n} f_{n^{\prime}}^{-\theta}}{\sum_{n^{\prime}=1}^{N} \gamma_{n^{\prime} n} f_{n^{\prime}}^{-\theta}}
$$

where $v_{n^{\prime} n}$ is the share of value added from country $n^{\prime}$ in final consumption of the representative consumer in country $n$. Throughout, we will refer to $\left\{v_{n^{\prime} n}\right\}_{n^{\prime}, n}$ as the matrix of international value-added linkages.

Market clearing in international goods and domestic factor markets entails

$$
r_{n} K_{n}+w_{n} L_{n}=f_{n} K_{n}^{\alpha} H_{n}^{1-\alpha}=\sum_{n^{\prime}=1}^{N} v_{n n^{\prime}}\left(f_{n^{\prime}} K_{n^{\prime}}^{\alpha} H_{n^{\prime}}^{1-\alpha}+T_{n^{\prime}}\right)
$$

where $H_{n} \equiv h_{n} L_{n}$ denotes productivity-adjusted labour, or "human capital". The set of factor costs $\left\{f_{n}\right\}_{n}$ constitutes an equilibrium price vector if it satisfies (7) and (8) for given parameters $\alpha, \theta,\left\{\gamma_{n^{\prime} n}\right\}_{n^{\prime}, n}$, given stocks of physical and human capital, and given international transfers. By Walras' Law, (7) and (8) uniquely determine equilibrium factor costs relative to some arbitrarily chosen numéraire. 
We define $Y_{n}$ as the real GDP of country $n$ evaluated at consumer prices. Then

$$
Y_{n} \equiv \frac{r_{n} K_{n}+w_{n} L_{n}}{P_{n}}=\frac{f_{n}}{\left(\sum_{n^{\prime}=1}^{N} \gamma_{n^{\prime} n} f_{n^{\prime}}^{-\theta}\right)^{-\frac{1}{\theta}}} A_{n} K_{n}^{\alpha} H_{n}^{1-\alpha}
$$

Real GDP of country $n$ is determined by domestic production factors - with the familiar Cobb-Douglas functional form over domestic physical and human capital -, country- $n$ productivity and the factor cost of country $n$ relative to a weighted index of all countries' factor costs.

The "relative factor cost" term in (9) encapsulates our open-economy generalisation of the conventional development-accounting equation. For given factor endowments, productivities and factor costs, a country $n$ with a high factor cost relative to its key value-added suppliers (for which it has a large $\gamma_{n^{\prime} n}$ ) will enjoy a higher level of real GDP. Such a situation reflects favourable terms of trade, which allow $n$ to consume more foreign value added for any domestic value added sold. In turn, equations (7) and (8) illustrate what gives rise to international factor-cost differences. For given factor endowments and international transfers, those countries whose value added is sourced by markets with relatively large expenditure (i.e. relatively large $\left.f_{n} K_{n}^{\alpha} H_{n}^{1-\alpha}+T_{n}\right)$ will enjoy higher equilibrium factor costs. In this way, the "relative factor cost" term captures the influence of a countries' international value-added linkages on their real GDP.

\subsection{Relationship with the Development-Accounting Literature}

\subsubsection{Development-Accounting Equation}

Letting small caps denote variables in per-worker terms, e.g. $x_{n} \equiv X_{n} / L_{n}$, and taking logs, we can write (9) as

$$
\ln y_{n}=\ln k_{n}^{\alpha} h_{n}^{1-\alpha}+\ln \frac{f_{n}}{\left(\sum_{n^{\prime}=1}^{N} \gamma_{n^{\prime} n} f_{n^{\prime}}^{-\theta}\right)^{-\frac{1}{\theta}}}+\ln A_{n} .
$$

Equation (10) shows that the log real income per worker of country $n$ can be decomposed into three parts: i) a term depending on the domestic per-worker capital stock and labour productivity, ii) the "relative factor cost" term, and iii) a total factor productivity "residual". ${ }^{11}$

\footnotetext{
${ }^{11}$ Note that "productivity" enters (10) in three distinct guises: via the labour-augmenting productivity terms, $\left\{h_{n}\right\}_{n}$, via the parameters which govern the patterns of international value-added linkages, $\left\{\gamma_{n^{\prime} n}\right\}_{n^{\prime}, n}$, and via the aggregate productivity terms $\left\{A_{n}\right\}_{n}$. What differentiates the first two from the third is that, in our development-accounting exercise, the variation of the former across countries (country-pairs) will be disciplined with external information. Meanwhile, we will permit
} 
In the special case $\gamma_{n n}=1$ and $\gamma_{n^{\prime} n}=0$ for all $n^{\prime} \neq n$, which implies that country $n$ has no use for foreign goods, equation (10) reduces to

$$
\ln y_{n}=\ln k_{n}^{\alpha} h_{n}^{1-\alpha}+\ln A_{n}
$$

This expression corresponds to the standard aggregate Cobb-Douglas production function which is widely used in macroeconomics. The development accounting literature employs (11) to assess what part of income differences between countries can be explained by differences in quantifiable endowments of production factors notably, per-worker capital stocks and labour productivities - and how much must be attributed to non-observable differences in "total factor productivity". The literature proceeds by obtaining direct measures of production factors, calibrating the parameter $\alpha$, and treating TFP as a residual.

Equation (10) demonstrates that we can think of (11) as the special case of a more general model which allows for an arbitrary set of international value added linkages between countries. In the more general case, for given $\left\{\gamma_{n^{\prime} n}\right\}_{n^{\prime}, n}$, other countries' production factors and international transfers affect real GDP in country $n$ via (7) and (8), as discussed in the previous section.

\subsection{2 success and ignorance}

Consider a general development-accounting equation along the lines of (10) or (11):

$$
\ln y_{n}=\ln y_{n}^{E \cdot}+\ln A_{n}^{E}
$$

where $\ln y_{n}^{E \text {. }}$ collects the components of log per-worker real GDP which can be measured directly, and $\ln A_{n}^{E}$ is the residual portion which is attributed to unobserved TFP. A simple variance decomposition yields

$$
\operatorname{Var}\left(\ln y_{n}\right)=\operatorname{Var}\left(\ln y_{n}^{E \cdot}\right)+\operatorname{Var}\left(\ln A_{n}^{E \cdot}\right)+2 \operatorname{Cov}\left(\ln y_{n}^{E \cdot}, \ln A_{n}^{E \cdot}\right)
$$

Caselli (2005) measures the "success" of his benchmark development accounting exercise by

$$
\text { success }^{E \cdot} \equiv \frac{\operatorname{Var}\left(\ln y_{n}^{E \cdot}\right)}{\operatorname{Var}\left(\ln y_{n}\right)},
$$

i.e. by the share of cross-country variation in $\ln y_{n}$ which can be explained with

variation of the latter to capture all unexplained differences in real per-worker incomes. In this sense, our exercise does not deny the role of productivity in explaining international income differences in general, but only seeks to reduce the reliance of development accounting on the particular set of residual "catch-all" productivities $\left\{A_{n}\right\}_{n}$. 
observables. An alternative, inverse performance statistic is

$$
\text { ignorance }^{E \cdot} \equiv \frac{\operatorname{Var}\left(\ln A_{n}^{E \cdot}\right)}{\operatorname{Var}\left(\ln y_{n}\right)} \text {, }
$$

i.e. the share of cross-country variation in $\ln y_{n}$ which must be attributed to variation in the "ignorance" TFP residual. If observables could perfectly explain countries' incomes, the value of success ${ }^{E}$. would be 1 and the value of ignorance $^{E \cdot}$ would be 0 .

Define

$$
\begin{gathered}
\ln y_{n}^{E D} \equiv \ln k_{n}^{\alpha} h_{n}^{1-\alpha}, \quad \ln A_{n}^{E D} \equiv \ln \frac{f_{n}}{\left(\sum_{n^{\prime}=1}^{N} \gamma_{n^{\prime} n} f_{n^{\prime}}^{-\theta}\right)^{-\frac{1}{\theta}}}+\ln A_{n}, \\
\ln y_{n}^{E L} \equiv \ln k_{n}^{\alpha} h_{n}^{1-\alpha}+\ln \frac{f_{n}}{\left(\sum_{n^{\prime}=1}^{N} \gamma_{n^{\prime} n} f_{n^{\prime}}^{-\theta}\right)^{-\frac{1}{\theta}}}, \quad \ln A_{n}^{E L} \equiv \ln A_{n},
\end{gathered}
$$

where $y^{E D}$ and $y^{E L}$ respectively represent the portions of income explained with domestic factors only, and with domestic factors and linkages; while $A^{E D}$ and $A^{E L}$ represent the respective implied TFP residuals. Employing these definitions in (14) and (15), we obtain success ${ }^{E D}$ and ignorance ${ }^{E D}$ as the measures of developmentaccounting "success" which would be obtained using the traditional, closed-economy framework. By contrast, success ${ }^{E L}$ and ignorance ${ }^{E L}$ would prevail in the generalised framework with international linkages. This highlights the potential importance of incorporating countries' international linkages into development accounting: if valueadded linkages are a quantitatively significant determinant of countries' incomes, traditional development accounting exercises would incorrectly attribute their effect to domestic total factor productivity, inflating ignorance at the expense of success.

So as to be able to compare our findings with Caselli's (2005), we report the success of our development-accounting exercises in each case below. However, our preferred statistic for evaluating these exercises is ignorance, for two reasons. First, ignorance is bounded below by 0 , while success may exceed 1. Second, introducing additional observables in a development-accounting equation may raise success without reducing ignorance. This makes ignorance a more suitable statistic for comparing the performance of different development-accounting exercises: a superior exercise - in terms of reducing the reliance of development accounting on unobserved TFP differences - will always reduce ignorance. ${ }^{12}$

\footnotetext{
${ }^{12}$ To see the second point, suppose we were to compare two development-accounting equations:

$$
\begin{aligned}
& \ln y_{n}=\ln y_{n}^{E D}+\ln A_{n}^{E D}, \\
& \ln y_{n}=\ln y_{n}^{E L}+\ln A_{n}^{E L},
\end{aligned}
$$
}




\section{Development Accounting}

\subsection{Data}

\subsubsection{Incomes, Factor Endowments and Trade Balances}

To perform our updated development accounting exercise we require data on countries' incomes, endowments of production factors, trade balances and on their international value-added linkages. Data on factor endowments is assembled from two standard sources: the Penn World Tables (PWT, edition 9.0) and the latest edition of the educational attainment database by Barro and Lee (2013). For ease of comparison with a benchmark development-accounting exercise in Caselli (2005), we construct factor-endowment data ourselves, closely following the methods described in that paper. Details are provided in Appendix A.2. ${ }^{13}$

\section{[Insert Table 1 here]}

Table 1 reports summary statistics of the final data on PPP-adjusted GDP per worker $\left(y_{n}\right)$, capital stock per worker $\left(k_{n}\right)$ and human capital per worker $\left(h_{n}\right)$ in the years 1996 and 2006 for the countries in our sample. The size of our country sample is limited to 40 economies (plus "rest of the world") by the coverage of the World Input Output Database (WIOD, see Timmer et al., 2015), our main source of data on international linkages. ${ }^{14}$

The WIOD also allows us to gauge the size of our sample countries' net imports, corresponding to the "transfers" in our model. In addition to describing the factor data, Table 1 reports summary statistics for net imports as a share of U.S. GDP $\left(t_{n}\right)$ in 1996 and 2006.

\subsubsection{International Value-Added Linkages}

The WIOD contains annual global input-output tables, built from domestic inputoutput tables and international trade data. The database covers all economic activity of its sample countries, divided into 40 broad use categories - 35 industries, and 5 final where $\ln y_{n}^{E L} \equiv \ln y_{n}^{E D}+\ln F_{n}$. A few lines of algebra show that

$$
\begin{array}{cccc}
\text { sucess }^{E L} \geq \text { success }^{E D} & \Leftrightarrow & 0 \leq \frac{1}{2} \operatorname{Var}\left(\ln F_{n}\right)+\operatorname{Cov}\left(\ln y_{n}^{E D}, \ln F_{n}\right) \\
\text { ignorance }^{E L} \leq \text { ignorance }^{E D} & \Leftrightarrow & \frac{1}{2} \operatorname{Var}\left(\ln F_{n}\right)+\operatorname{Cov}\left(\ln y_{n}^{E D}, \ln F_{n}\right) \leq \operatorname{Cov}\left(\ln y_{n}, \ln F_{n}\right) .
\end{array}
$$

\footnotetext{
${ }^{13}$ However, our quantitative findings are extremely robust to the use of alternative methods in constructing factor-endowment data. Appendix A.2 provides an overview of how (little) our findings are affected when we use different methods/sources for assembling factor data for our developmentaccounting exercise.

${ }^{14}$ Income and factor endowments for the "rest of the world" are constructed by aggregating the corresponding variables for all countries which report sufficient data in the PWT but do not belong to our sample of 40 economies.
} 
sectors (corresponding to final consumption expenditure by households, by the public sector and for investment and inventory accumulation). A typical cell represents the current dollar value of expenditure by use category $s$ in country $n$ on use category $s^{\prime}$ in country $n^{\prime}$.

The WIOD reports tables for each year in the period 1995-2011. For a given year, we use this information to derive the final use by country $n$ of value added generated in each country $n^{\prime}$, corresponding to our definition of $v_{n^{\prime} n}$ in Section 2. In doing so, we follow Johnson and Noguera (2012) and Timmer et al. (2013). The procedure is briefly outlined in Appendix A.2, with more details available in those papers.

Figure 1 offers a graphical overview of the matrix $\left\{v_{n^{\prime} n}\right\}_{n^{\prime}, n}$, calculated for the year 2006. Each dot in the figure represents the share of value added from the verticalaxis country ("country $n^{\prime \prime \prime}$ ) used in final expenditure of the horizontal-axis country ("country $n$ "), with the size of the dot indicating the magnitude of the share. The magnitude of the entries ranges from almost 0 to .9 .

\section{[Insert Figure 1 here]}

Two features of the data are immediately apparent from Figure 1. First, even the smallest entry on the diagonal of the matrix (.54) is considerably larger than the largest off-diagonal element (.12), indicating that countries' own value added accounts for the large majority of their overall final use of value added. Second, there are a number of countries whose value added is used to a significant extent in the final expenditure of all other countries (resulting in "strong" horizontal lines in the figure). Those countries - notably, the United States, Japan, Germany and China - appear to be large in terms of the shares of world population and GDP. Although Figure 1 is based on data from the year 2006, the same stylised facts are observed in any year covered by the WIOD.

\section{[Insert Figure 2 here]}

In Figure 2, we investigate the stability over time of our matrix of international linkages, $\left\{v_{n^{\prime} n}\right\}_{n^{\prime}, n}$. The left-hand panel plots the value of a particular off-diagonal entry in the matrix from the year 2006 against the value of the same off-diagonal entry from 1996. The right-hand panel does the same for on-diagonal entries. No change in a particular entry over time would place it on the forty-five degree line (shown as a dashed line in both panels). As can be seen from the right-hand panel, the value of nearly all diagonal matrix entries has declined between 1996 and 2006, reflecting a growing integration of international value chains that has been well documented elsewhere. ${ }^{15}$ The pattern emerging from the left-hand panel is less clear, showing both increases and decreases in the value-chain integration of individual country pairs. A

\footnotetext{
${ }^{15}$ For example, see Hummels et al. (2001), Yi (2003) and Timmer et al. (2013).
} 
common feature of both panels is that the magnitude of most changes in $\left\{v_{n^{\prime} n}\right\}_{n^{\prime}, n}$ in the period 1996-2006 appears to have been small.

\section{2 "Traditional" Development Accounting}

\subsubsection{Calibrating the "Traditional" Model}

As defined in Section 2.3.2, $y_{n}^{E D}$ constitutes the portion of country- $n$ income which would be explained by traditional development-accounting exercises that disregard the role of international linkages. We now calculate $\left\{y_{n}^{E D}\right\}_{n}$ using per-worker capital stocks and labour productivity from the data described in Section 3.1, and setting the capital share $\alpha$ to the value 1/3, in line with Caselli (2005) as well as much of the macroeconomics literature. We then obtain $\left\{A_{n}^{E D}\right\}_{n}$ as the residual portions of perworker GDPs not captured by $\left\{y_{n}^{E D}\right\}_{n}$. This, in turn, allows us to derive success ${ }^{E D}$ and ignorance ${ }^{E D}$.

\subsubsection{Results: Domestic Factors Only}

The first column in the left-hand and right-hand panels of Table 2 reports success ${ }^{E D}$ and ignorance ${ }^{E D}$ using data for our 40 economies from the years 1996 (left-hand panel) and 2006 (right-hand panel). This corresponds to Caselli's (2005) baseline development-accounting exercise. As the table shows, the variance of countries' log per-worker incomes is significantly larger than the variance of $\ln y_{n}^{E D}$, resulting in values of success of around one quarter and ignorance of around one third in 1996. The values for 2006 are of similar magnitude. Caselli (2005) reports his findings for different country samples in the year 1996. Although none of these samples perfectly overlaps with ours, the value of success from his "Europe" sample - which covers the largest share of countries contained in our group of 40 economies -is similar to ours at .23. The findings of our "traditional" development-accounting exercise (using only data on domestic factor endowments) are thus comparable to those of earlier studies.

\section{[Insert Table 2 here]}

\subsection{Development Accounting with International Linkages}

\subsubsection{Calibrating and Solving the General Model}

Our open-economy model in Section 2 introduces a range of new parameters $\left\{\gamma_{n^{\prime} n}\right\}_{n^{\prime}, n}$ and $\theta$ - relative to the standard development accounting framework (which only needs to calibrate a single parameter, $\alpha$ ). We proceed by calibrating $\left\{\gamma_{n^{\prime} n}\right\}_{n^{\prime}, n}$ so as to match countries' value-added linkages in the data, and presenting results for a range of values of $\theta$. To build intuition, Section 3.3.2 reports results for the special 
case in which $\theta \rightarrow 0$ in detail. Section 3.3.3 reports results for a range of positive values of $\theta$, and discusses plausible choices for this parameter. We find that, for any plausible value of $\theta$, we obtain values of success and ignorance which improve significantly on the performance of the "traditional" closed-economy development accounting framework.

For given factor costs and a given value of $\theta$, we can choose $\left\{\gamma_{n^{\prime} n}\right\}_{n^{\prime}, n}$ so that our model matches the matrix of observed value-added linkages $\left\{v_{n^{\prime} n}\right\}_{n^{\prime}, n}$ perfectly using equation (7). In matching value-added linkages, we have one free parameter per country, so we impose the normalisation $\sum_{n^{\prime}} \gamma_{n^{\prime} n}=1 .{ }^{16}$

Observed value-added linkages in turn imply a cross-country distribution of factor costs, $\left\{f_{n}\right\}_{n}$, from equation (8), independently of the value of $\theta$. Choosing country- $N$ factor cost as the numeraire, we can write (8) in matrix form as

$$
\left[\begin{array}{c}
f_{1} K_{1}^{\alpha} H_{1}^{1-\alpha} \\
\vdots \\
f_{N-1} K_{N-1}^{\alpha} H_{N-1}^{1-\alpha}
\end{array}\right]=\mathbf{V}\left[\begin{array}{c}
f_{1} K_{1}^{\alpha} H_{1}^{1-\alpha}+T_{1} \\
\vdots \\
f_{N-1} K_{N-1}^{\alpha} H_{N-1}^{1-\alpha}+T_{N-1}
\end{array}\right]+\mathbf{v}_{. \mathbf{N}}\left(K_{N}^{\alpha} H_{N}^{1-\alpha}+T_{N}\right)
$$

where

$$
\mathbf{V} \equiv\left[\begin{array}{ccc}
v_{11} & \ldots & v_{1, N-1} \\
\vdots & & \vdots \\
v_{N-1,1} & \ldots & v_{N-1, N-1}
\end{array}\right] \quad \mathbf{v . N} \equiv\left[\begin{array}{c}
v_{1 N} \\
\vdots \\
v_{N-1, N}
\end{array}\right]
$$

Using the fact that $T_{N}=-\sum_{n \neq N} T_{n}$, (18) implies

$$
f_{n}=u_{n} \frac{K_{N}^{\alpha} H_{N}^{1-\alpha}}{K_{n}^{\alpha} H_{n}^{1-\alpha}},
$$

where $u_{n}$ is the typical element of the vector

$$
\left[\begin{array}{c}
u_{1} \\
\vdots \\
u_{N-1}
\end{array}\right]=(\mathbf{I}-\mathbf{V})^{-1}\left\{(\mathbf{V}-\mathbf{v} . \mathbf{N} \mathbf{1})\left[\begin{array}{c}
t_{1} \\
\vdots \\
t_{N-1}
\end{array}\right]+\mathbf{v} . \mathbf{N}\right\}
$$

and we define $\mathbf{1}$ as an $N-1$ row vector of ones, $t_{n}$ as country $n$ 's net imports as a share of numeraire-country GDP, and $u_{N}=1$. Put in words, we can express $f_{n}$ explicitly as a function of country- $n$ factor endowments, country- $N$ factor endowments, the matrix of empirically observed value-added linkages $\left\{v_{n^{\prime} n}\right\}_{n^{\prime}, n}$, and the distribution of empirically observed trade imbalances, $\left\{t_{n}\right\}_{n}$. Throughout, we will let the United States be our numeraire country.

Using $\left\{f_{n}\right\}_{n}$ thus derived, a value for $\theta$, and the calibrated values of $\left\{\gamma_{n^{\prime} n}\right\}_{n^{\prime}, n}$ to

\footnotetext{
${ }^{16}$ This normalisation permits us to characterise formally the special case of the model we discuss in Section 3.3.2.
} 
reconcile (7) with the data, we obtain an expression for the "relative factor cost" term in (10). This allows us to compute $\left\{y_{n}^{E L}\right\}_{n}$ and $\left\{A_{n}^{E L}\right\}_{n}$ and, hence, success ${ }^{E L}$ and ignorance $^{E L}$.

\subsubsection{Results: Domestic Factors and Linkages $(\theta \rightarrow 0)$}

In the special case $\theta \rightarrow 0$, the consumer preferences given in (1) converge to a CobbDouglas form. As a result, international value-added linkages converge to a CobbDouglas expenditure system. Calibrating the parameters $\left\{\gamma_{n^{\prime} n}\right\}_{n^{\prime}, n}$ to match valueadded trade flows then amounts to

$$
v_{n^{\prime} n}=\gamma_{n^{\prime} n}
$$

This special case is attractive because it is highly tractable, and because the CobbDouglas expenditure system is a popular benchmark for modelling input-output (and, by extension, value-added) linkages in a range of applications. ${ }^{17}$

It is straightforward to show that

$$
\lim _{\theta \rightarrow 0} \ln y_{n}=\ln k_{n}^{\alpha} h_{n}^{1-\alpha}+\ln \left[\prod_{n^{\prime}=1}^{N}\left(\frac{u_{n}}{u_{n^{\prime}}} \frac{K_{n^{\prime}}^{\alpha} H_{n^{\prime}}^{1-\alpha}}{K_{n}^{\alpha} H_{n}^{1-\alpha}}\right)^{v_{n^{\prime} n}}\right]+\ln A_{n} .
$$

The second term on the right-hand side of equation (23) illustrates what underlies the contribution of the "relative factor cost" term to per-capita incomes in our model. Everything else constant, if country $n$ is abundant in production factors relative to its trading partners (i.e. it has a relatively large $K_{n}^{\alpha} H_{n}^{1-\alpha}$ ), its factor cost will be relatively low, depressing its real income. Meanwhile, the term $u_{n}$ summarises "world demand" for country- $n$ value added. For given factor endowments, a relatively large $u_{n}$ is associated with relatively high demand for country- $n$ factor services, which causes the factor cost of country $n$ to be relatively large, boosting its real income. Finally, the effect of conditions in each individual country $n^{\prime}$ on the "relative factor cost" term of country- $n$ is moderated by $v_{n^{\prime} n}$, which determines the importance of $n^{\prime}$ in the final-consumption basket of $n$.

The second column in the left-hand and right-hand panels of Table 2 reports success and ignorance if we engage in development accounting using equation (23) combined with data on production factors, value-added linkages and trade balances. We obtain values of success equal to .49 in 1996 and .50 in 2006. Thus, the incorporation of the "relative factor cost" term doubles the share of the cross-country variation in incomes which our updated development accounting framework can explain. The

\footnotetext{
${ }^{17}$ See Fadinger et al. (2015) for a recent example of the use of a Cobb-Douglas model of inputoutput linkages in a domestic macroeconomics context, and Johnson (2014) and Caliendo and Parro (2015) for examples of its use in an international context.
} 
value of ignorance is reduced to .14 in 1996, and .11 in 2006. Hence, our "relative factor cost term" reduces income variation attributed to unobserved TFP differences by more than half.

\section{[Insert Figure 3 here]}

Figure 3 offers a graphical representation of our findings. For the year 2006, it plots $\ln y_{n}$ against $\ln y_{n}^{E D}$ (left-hand panel) and against $\ln y_{n}^{E L}$ (right-hand panel). For domestic factors (domestic factors and relative factor costs) to explain the variation in $\log$ per-capita incomes perfectly, $\ln y_{n}$ would have to equal $\ln y_{n}^{E D}\left(\ln y_{n}^{E L}\right)$ up to the value of a constant term - that is, the observations in the left-hand (right-hand) panel should be aligned along a line with an arbitrary intercept, and a slope of one. Clearly, this is not the case in either panel. However, the red line of best fit between $\ln y_{n}$ and $\ln y_{n}^{E L}$ has a slope of 1.3 , while the line of best fit between $\ln y_{n}$ and $\ln y_{n}^{E D}$ has a slope of 1.9. The difference in slopes is statistically significant at the $1 \%$ level, implying that our model with linkages comes significantly closer to explaining cross-country income variations as a result of observables than the traditional closed-economy framework. The figure also verifies that this result is not driven by a few "outlier" countries.

[Insert Figure 4 here]

To illustrate why the incorporation of the "relative factor cost" term improves results compared to conventional development accounting, we split the term into two components for the year 2006 - the $\log$ factor cost of each country, $\ln f_{n}$, and the $\log$ weighted factor costs of its value-added sources, $\ln \left(\sum_{n^{\prime}} \gamma_{n^{\prime} n} f_{n^{\prime}}^{-\theta}\right)^{-\frac{1}{\theta}}-$ and plot both against countries' observed real PPP-adjusted GDP in that year. The left-hand panel of Figure 4 displays the correlation of log model-implied factor costs with log per-worker real GDP in the data, the right-hand panel the correlation of log weighted source factor costs with log per-worker real GDP of that country. ${ }^{18}$ The lefthand panel demonstrates that the relative success of our open-economy development accounting exercise is owed to the strong positive correlation between model-implied country factor costs and per-worker real GDPs. Since countries rely largely but not exclusively on their own value added, the relationship between model-implied source factor costs (which "work against" own factor costs) and per-worker GDPs is weaker, as seen in the right-hand panel. As a result, the net effect of introducing both terms in the development accounting framework is to raise the correlation of the right-handside observables with actual log per-worker GDPs, boosting success and reducing ignorance.

\section{[Insert Figure 5 here]}

\footnotetext{
${ }^{18}$ Note that a country's consumer price index is distinct from the index of weighted source factor costs, as the former depends both on source factor costs and the country's aggregate productivity, $A_{n}$.
} 
Figure 5 shows that accounting for international value-added linkages in the calculation of country's productivity levels causes us to revise downward our assessment of TFP for some countries, and upwards for others, so that TFP levels become more similar overall. High model-implied factor costs (as in the cases of Luxembourg, Ireland and Denmark) are associated with downward revisions of TFP, while low model-implied factor costs (as in the cases of Cyprus, Malta and Bulgaria) are associated with upward revisions. This is intuitive: our framework attributes part of the relatively high per-worker GDP in Luxembourg to high factor costs, and part of the relatively low per-worker GDP in Bulgaria to relatively low factor costs. Without the "relative factor cost" term, a closed-economy development accounting exercise would attribute these income differences to differences in TFP. Consequently, it would overstate Luxembourg's TFP and understate Bulgaria's.

\subsubsection{Results: Domestic Factors and Linkages $(\theta>0)$}

The Cobb-Douglas special case explored above is illustrative but highly stylised: it suggests that the patterns of international value-added linkages are completely unresponsive to changes in the relative costs of value added sourced from different origin countries. Based on the evidence presented in Figure 1, this may not do justice to some of the determinants of international linkages: in the figure, countries with large endowments of physical and human capital (e.g. the U.S.) ship more value added to all foreign destinations than smaller countries. Once we allow for the possibility that $\theta$ may be strictly positive, our model would predict that such countries ship more value added abroad for given $\left\{\gamma_{n^{\prime} n}\right\}_{n^{\prime}, n}$, as their factor costs would be relatively low ceteris paribus. Hence, permitting $\theta>0$ allows us to capture a portion of the patterns in Figure 1 without relying on exogenous differences in the bilateral trade determinants, $\left\{\gamma_{n^{\prime} n}\right\}_{n^{\prime}, n}$.

While a strictly positive $\theta$ seems plausible, the exact calibration of this parameter hinges on its interpretation. In the Armington model of Section 2, $\theta$ represents the substitution elasticity between goods minus 1. Earlier studies in international macroeconomics have attributed values in the range 2-3 to this elasticity, suggesting values in the range 1-2 may be appropriate for $\theta$ (see Backus et al., 1994). However, $\theta$ also represents the "trade elasticity", i.e. the responsiveness of trade flows to changes in trade costs. ${ }^{19}$ Several studies have attempted to estimate the trade elasticity using data on bilateral trade flows and goods prices. While initial estimates were as large as 8, subsequent studies have found values closer to 4 (see Eaton and Kortum, 2002; Simonovska and Waugh, 2014). We adopt the intermediate $\theta=4$ as our baseline parameter calibration. At the same time, in Figure 6 we present results for a range of

\footnotetext{
${ }^{19}$ This is true in the Armington model of Section 2 - as can be seen from equations (5)-(7) - and in the alternative Eaton-Kortum model we describe in the appendix (see Section A.1.3).
} 
values of $\theta$ between 0 and 8, using 2006 data, to illustrate how the choice of $\theta$ affects our findings.

\section{[Insert Figure 6 here]}

The left-hand panel plots values of success, and the right-hand panel values of ignorance, against $\theta$ (dashed lines provide the reference values from the standard development-accounting framework). As can be seen from the figure, over a plausible range of $\theta$, the Cobb-Douglas special case turns out to present a conservative picture of the relative success of our development-accounting exercise with value-added linkages: higher values of $\theta$ yield higher values of success and, up to a point, lower values of ignorance. Beyond $\theta$-values of 2 , success exceeds 1 - implying that our framework predicts more variation in incomes than observed in the data. At this point, variation in TPF once again becomes necessary to explain why some countries are not as rich relative to others as our accounting exercise would suggest, which raises ignorance.

\section{[Insert Figure 7 here]}

Figure 7 provides an intuition for this finding. It contrasts the income correlations of countries' own factor costs and their weighted source factor costs for the case $\theta \rightarrow 0$, already seen in Figure 4, with the case $\theta \rightarrow \infty$. As noted in Section 3.3.1, given data on international value-added linkages, countries' model-implied factor costs can be calculated independently of the value of $\theta$. For this reason, the left-hand panel of Figure 7 is identical in both cases. Yet this is not true for weighted source factor costs: as $\theta \rightarrow \infty$, all countries' source factor-cost indices converge to a single number: the maximum global factor cost. ${ }^{20}$ Therefore, as $\theta \rightarrow \infty$, the variation in $\ln f_{n}$ remains unaltered, while the variation in $-\frac{1}{\theta} \ln \left(\sum_{n^{\prime}} \gamma_{n^{\prime} n} f_{n^{\prime}}^{-\theta}\right)$ disappears. Since the former is highly correlated with per-capita incomes, and variation in the latter "works against" the former, this increases success and lowers ignorance - up to the point at which the variation in incomes explained by the model equals the variation in actual percapita incomes. Beyond this point, ignorance rises once again as success begins to exceed 1.

\section{[Insert Table 3 here]}

Table 3 reports values of success and ignorance for different values of $\theta$. The case $\theta=1.8$ results in the smallest value of ignorance, i.e. the least reliance on TFP differences in explaining income variation in the data (the value of success is .94 in this case). The case $\theta=4$ corresponds to our preferred calibration of the parameter.

\footnotetext{
${ }^{20}$ For given $\left\{\gamma_{n^{\prime} n}\right\}_{n^{\prime}, n}$, a rise in $\theta$ would cause countries to source relatively more value added from locations with lower factor costs. This implies that, in order for our calibration to match the given $\left\{v_{n^{\prime} n}\right\}_{n^{\prime}, n}$ as $\theta$ increases, $\gamma_{n^{\prime} n}$ needs to rise disproportionally for $n^{\prime}$ with relative high factor costs. In the limit, this implies that $\gamma_{n^{*} n} \rightarrow 1$ for all $n$, where $n^{*} \in \arg _{n \in N} \max \left\{f_{1}, \ldots, f_{N}\right\}$.
} 
The Cobb-Douglas special case $(\theta \rightarrow 0)$ and our preferred calibration $(\theta=4)$ result in development-accounting equations which require similarly low variation in unobserved TFPs to explain observed international income differences. Any value of $\theta$ between these cases results in even less ignorance. Therefore, our conclusion from Section 3.3.2 remains unaltered: accounting for relative factor costs among open economies reduces income variation attributed to unobserved TFP differences by more than half.

The model-implied TFP levels with $\theta=4$ are shown in Figure 8. The upward revision of TFP levels at the bottom end of the distribution is now even more striking than in Figure 5. Choosing a larger value for $\theta$ implies an even lower relative factor cost for some of the poorest countries in our sample. As a result, equation (10) can account for international income differences while assigning TFP levels to poorer countries which are comparable to (and in some cases higher than) the productivities of the richest economies.

\section{[Insert Figure 8 here]}

\subsubsection{Country-Specific Labour Shares}

So far, we have assumed that the labour intensity of production $(1-\alpha)$ is the same across countries. We have done so to replicate the baseline development-accounting exercise performed in Caselli (2005), as well as to simplify the exposition of our findings. With Cobb-Douglas production and a common labour intensity, we should observe a constant labour share of income across countries. However, as documented by Gollin (2002) and - more recently - Karabarbounis and Neiman (2014), there appears to be a lot of cross-country variation in the labour share.

It is easy to reconcile our framework with this observation by assuming that countries operate Cobb-Douglas technologies with different labour intensities. This yields a straightforward generalisation of equations (8) and (9):

$$
\begin{gathered}
f_{n} K_{n}^{\alpha_{n}} H_{n}^{1-\alpha_{n}}=\sum_{n^{\prime}=1}^{N} v_{n n^{\prime}}\left(f_{n^{\prime}} K_{n^{\prime}}^{\alpha_{n^{\prime}}} H_{n^{\prime}}^{1-\alpha_{n^{\prime}}}+T_{n^{\prime}}\right) \\
Y_{n}=\frac{f_{n}}{\left(\sum_{n^{\prime}=1}^{N} \gamma_{n^{\prime} n} f_{n^{\prime}}^{-\theta}\right)^{-\frac{1}{\theta}}} A_{n} K_{n}^{\alpha_{n}} H_{n}^{1-\alpha_{n}} .
\end{gathered}
$$

We can now perform development accounting as described in Section 3.3.1, but calibrating $\left\{\alpha_{n}\right\}_{n}$ to match information on countries' observed labour shares (which is provided in PWT 9.0). Table 4 reports the results from performing the same development-accounting exercises which underlie the findings reported in Table 3, but allowing for PWT-reported, country-specific labour shares.

[Insert Table 4 here] 
Incorporating country-specific labour shares significantly increases the success of a traditional development accounting exercise, as can be seen from the first column of Table $4 .^{21}$ However, it also dramatically raises ignorance. The extent to which this generalisation can help account for income differences in our country sample is thus ambiguous at best. Nevertheless, once we incorporate relative factor costs in the development-accounting equation (in the second to fourth columns), we obtain both higher values of success and significantly lower values of ignorance, regardless of the value of $\theta$. Therefore, the introduction of country-specific labour shares does not affect our qualitative conclusions from Sections 3.3.2 and 3.3.3.

\subsubsection{Relative Factor Costs versus $C G D P^{e} / C G D P^{\circ}$ Gaps}

Since edition 8.0, the PWT has provided two alternative measures of real GDP for cross-country comparisons. The first, labelled "expenditure-side" real GDP $\left(C G D P_{n}^{e}\right)$, deflates the dollar GDP of country $n$ by its price level of domestic absorption. It represents the traditional measure of PPP-adjusted GDP, which takes account of differences in final-expenditure price levels across countries, capturing the consumption value of a country's final output. Conceptually, $C G D P_{n}^{e}$ corresponds to $Y_{n}$ in our model, as defined in equation (9).

The second, labelled "output-side" real GDP $\left(C G D P_{n}^{o}\right)$, deflates nominal GDP in a manner designed to better reflect the productive capacity of country $n$. The introduction of this second, distinct real GDP concept reflects the recognition that the consumption and production baskets of an open economy need not coincide. Hence, an "output-side" deflator of GDP needs to adopt different price weights from an "expenditure-side" deflator. As data on output prices and quantities is not readily available for a large set of countries, the PWT constructs a price deflator with output weights from the traditional PWT "expenditure-side" deflator by subtracting countries' weighted import prices and adding their weighted export prices (see Feenstra et al., 2009; 2015). ${ }^{22}$

Feenstra et al. (2015) argue that the difference between the two deflators reflects the terms of trade, and they introduce $C G D P_{n}^{e} / C G D P_{n}^{o}$ into a standard developmentaccounting equation to "account for differences in $C G D P_{n}^{e}$ per capita by variation in the gap between $C G D P_{n}^{e}$ and $C G D P_{n}^{o}$ - the effect of the terms of trade on standards of living" (p. 3179). Formally, defining $G_{n} \equiv C G D P_{n}^{e} / C G D P_{n}^{o}$, Feenstra et al. (2015)

\footnotetext{
${ }^{21}$ Feenstra et al. (2015) report the same finding for a larger sample of countries. See Feenstra et al. (2015), Table 1 and text, p. 3179.

${ }^{22}$ Note that only the unit values, not prices, of exports and imports are available across a large group of countries. Since unit values of goods shipped do not correct for the likely sizeable differences in quality, the PWT follows Feenstra and Romalis (2014) in estimating quality-adjusted prices of exports and imports from unit values using a monopolistic-competition trade model.
} 
perform development accounting using

$$
\ln y_{n}=\ln G_{n}+\ln k_{n}^{\alpha} h_{n}^{1-\alpha}+\ln A_{n}
$$

They find that allowing for variation in $\ln G_{n}$ across countries does little to raise the share of cross-country income variation which can be explained with data. ${ }^{23}$

In order to understand the differences between their findings and ours, it is instructive to compare the $C G D P_{n}^{e} / C G D P_{n}^{o}$ "gap" implied by our model with the "relative factor cost" term which plays a crucial role in our analysis above. Following Feenstra et al. (2009; 2015), we show in Appendix A.3 that the corresponding expression for $C G D P_{n}^{o}$ in our model is

$$
C G D P_{n}^{o} \equiv \gamma_{n n}^{\frac{1}{\theta}} A_{n} K_{n}^{\alpha} H_{n}^{1-\alpha}
$$

From (9) and (27), it is easy to see that $G_{n}$ is related to, but does not equal, our "relative factor cost" term. Specifically,

$$
F_{n} \equiv \frac{f_{n}}{\left(\sum_{n^{\prime}} \gamma_{n^{\prime} n} f_{n^{\prime}}^{-\theta}\right)^{-\frac{1}{\theta}}}=\gamma_{n n}^{\frac{1}{\theta}} G_{n}
$$

The intuition for the relationship between $F_{n}$ and $G_{n}$ implied by (28) is as follows: while $G_{n}$ only corrects for the difference in weights between the consumption and production basket of country $n$ for given "expenditure-side" prices, $F_{n}$ also corrects for any difference between the country- $n$ consumer and producer prices themselves. The latter difference is captured by $\gamma_{n n}^{\frac{1}{\theta}}$. In turn, unless there is little variation in $\gamma_{n n}$ across countries, equation (28) implies that $\ln F_{n}$ and $\ln G_{n}$ need not be strongly correlated. Tables 5 and 6 confirm this using PWT data and output from our model calibration.

\section{[Insert Table 5 here]}

Table 5 presents summary statistics for our sample countries in 2006 of the log "gaps" reported in PWT (in the PWT column), and contrasts them with output from our model using our preferred trade elasticity $(\theta=4$, in the Model columns): the log "relative factor costs" and model-implied log "gaps". It is evident from the table that the mean and standard deviation of our model-implied "gaps" differ significantly from the mean and standard deviation of our model-implied "relative factor cost" terms, but resemble relatively closely the mean and standard deviation of the PWTreported "gaps". Table 6 presents pairwise correlations. It shows that there is only a modest correlation between $\ln F_{n}$ and the PWT-reported as well as the model-implied log "gaps". Those correlations are not statistically significant at conventional levels.

\footnotetext{
${ }^{23}$ See Feenstra et al. (2015), Table 1, "Baseline" column, p. 3179.
} 
Meanwhile, there is a robust positive correlation between the PWT-reported and the model-implied "gaps", which is statistically significant at the $1 \%$ level.

$$
\text { [Insert Table } 6 \text { here] }
$$

Two key points emerge from this comparison. First, our model suggests that $\ln G_{n}$ should not be expected to provide a close approximation of $\ln F_{n}$ for developmentaccounting purposes. Second, our model can plausibly generate $C G D P_{n}^{e} / C G D P_{n}^{o}$ "gaps" which resemble those reported in the PWT. The difference between our findings and those reported in Feenstra et al. (2015) thus does not stem primarily from the output of our model calibration disagreeing with the PWT-reported "gaps". Rather, it stems from the fact that these "gaps" constitute only a part of the relative-price adjustment needed to perform open-economy development accounting consistent with standard trade models, along the lines of the model in Section 2.

\section{[Insert Table 7 here]}

To reinforce this message, we perform development accounting on the basis of equation (26), using both PWT-reported and model-implied "gaps" for our sample countries in 2006. Table 7 gives an overview of the results. For convenience, the first column reproduces the results of a traditional closed-economy development accounting exercise, as in the first columns of Tables 2 and 3. The second column confirms that, just as in Feenstra et al. (2015), including the PWT-reported "gaps" in an otherwise standard development-accounting equation raises success only slightly, and does little to reduce ignorance. The third column highlights that very similar results would be obtained if we used model-implied "gaps". These findings suggest that the $C G D P_{n}^{e} / C G D P_{n}^{o}$ "gaps" currently reported in PWT and the "relative factor costs" used throughout this paper contain different, but complementary, information about the effect of openness on countries' incomes.

\section{Counterfactuals}

\subsection{Calibration}

In Section 2, we derived a generalisation of the standard development-accounting equation for a setting of open economies. In Section 3, we showed how this equation can be taken to the data. Throughout, we have relied on insights from standard quantitative trade models of the kind which have been used in previous studies to analyse the impact of trade policies on countries' incomes. In this section, departing from our findings in Section 3, we use our framework to perform a few counterfactuals in the spirit of some of these earlier papers. The purpose of this is twofold. First, it allows us to highlight that our findings above are consistent with existing research 
which has explored the impact of trade on incomes through counterfactuals. Second, it illustrates how changes in some observed features of the international environment would influence different countries' incomes through their effect on relative factor costs.

We begin by calibrating our model to data from the year 2006. We choose $\alpha=1 / 3$, $\theta=4$ for our key structural parameters (see the discussion in Section 3.3.3). Given 2006 data on countries' factor endowments and trade balances, $\left\{K_{n}, H_{n}, t_{n}\right\}_{n}$, we calibrate $\left\{\gamma_{n^{\prime} n}\right\}_{n^{\prime}, n}$ targeting empirical value-added trade linkages from that year as described in Section 3.3.1. We then attribute the residual part of income not explained by 2006 factor endowments and relative factor costs to aggregate TFP differences, $\left\{A_{n}\right\}_{n}$. Summary statistics for the 2006 distribution of factor endowments and trade balances can be found in Table 1. Table 8 reports summary statistics for the calibrated bilateral technology parameters and aggregate TFPs.

\section{[Insert Table 8 here]}

By construction, the calibrated model perfectly matches real per-capita incomes and the patterns of value-added trade in 2006. We proceed to consider two types of scenarios: i) the elimination of all trade imbalances; and ii) the disappearance of all value-added linkages in complete autarky.

\subsection{Scenarios}

\subsubsection{Balanced Trade}

Figure 9 reports the impact on real GDPs from imposing balanced trade $t_{n}=0$ for all $n$ ) in the 2006 calibration of our model. The changes are generally small, ranging from $-2.4 \%$ (Cyprus) to $+2.1 \%$ (Luxembourg), with most changes smaller than $1 \%$ in magnitude. They are also strongly negatively correlated with countries' initial net imports in 2006: the correlation between the log change in real GDP and $t_{n}$ is -.32 . This is consistent with countries experiencing a "transfer effect" (Keynes, 1929; Ohlin, 1929).

\section{[Insert Figure 9 here]}

The intuition of the "transfer effect" is well understood in international economics: in the presence of home-biased consumption patterns (here, high values of $v_{n n}$ ), trade imbalances raise real GDP in favour of net importers, as more expenditure is allocated to their goods, raising the relative price of their exports and their relative factor costs. By the same token, the terms of trade and relative factor costs of net exporters deteriorate. If trade imbalances are corrected, the reversal of the transfer effect should 
result in a rise in the real GDP of trade-surplus countries, and a fall in the real GDP of deficit countries. ${ }^{24}$

Dekle et al. (2007, 2008) use a multi-country Eaton-Kortum model calibrated to data from the year 2004 to analyse the effect of eliminating global imbalances on the nominal and real GDPs of 42 economies. In their most comparable counterfactual, they find real-GDP changes of similar magnitude to ours, ranging from $-.7 \%$ to $+3.5 \%$ in the extremes but "nearly always a fraction of a percent." 25 Our findings here thus gel with their conclusion that the effect of trade imbalances on real incomes is small for most countries.

\section{[Insert Figure 10 here]}

The effect of balancing global trade on countries' real per-capita consumption levels dwarves the effect on real per-capita GDPs, as can be seen from Figure 10. This is unsurprising, since

$$
\ln \frac{c_{n}^{\text {bal.trade }}}{c_{n}}=\ln \left(\frac{y_{n}^{\text {bal.trade }}}{y_{n}+\frac{T_{n} / L_{n}}{P_{n}}}\right)=\ln \left(\frac{y_{n}^{\text {bal.trade }}}{y_{n}}\right)-\ln \left(1+\frac{t_{n}}{u_{n}}\right)
$$

where the second equality can be shown to follow from (20). Correspondingly, there is near-perfect correlation between real-consumption and real-GDP changes (at .97) but the median change in per-capita consumption is $9.3 \%$ in magnitude, with changes ranging from $-23.0 \%$ (Cyprus) to $+44.3 \%$ (Luxembourg). ${ }^{26}$

Although we report the impact of balancing trade flows on real per-capita consumption levels for completeness, these figures need to be interpreted with care. While consumption technically constitutes the appropriate measure of welfare in our model, the static nature of our framework together with the assumption of exogenous trade balances preclude a robust welfare analysis. The latter would require trade imbal-

\footnotetext{
${ }^{24}$ In our multi-country setting a move to balance in a surplus country $n$ could, in principle, improve the terms of trade of a closely linked (here, high $v_{n^{\prime} n}$ ) deficit country $n^{\prime}$, counteracting or even overturning the effect of balanced trade on the GDP of $n^{\prime}$. However, such effects appear to be of second order in practice.

${ }^{25}$ Dekle et al. (2008) perform their counterfactuals under different assumptions about labour mobility and the adjustability of the range of goods produced by countries. Their long-run scenario - in which labour is perfectly mobile within countries, and the range of goods produced can fully adjust to shocks - is most comparable to our counterfactual here. Note that our qualitative and quantitative findings are similar to theirs despite the fact that they choose a significantly higher value for the trade elasticity $(\theta=8.3)$. Our own experiments with different values of $\theta$ suggest that the magnitude of "transfer effects" does not appear to be affected much by changes in the trade elasticity.

${ }^{26}$ The strikingly large effect of balancing trade flows on the real per-capita GDP and consumption of Cyprus is due to a trade deficit amounting to $23 \%$ of GDP reported for that country in the 2006 table of WIOD. Other sources report a much lower trade deficit for Cyprus in 2006 (3\% of GDP according to the World Development Indicators). For consistency, we use the WIOD figures throughout. Owing to the small magnitude of transfer effects, and the relatively small size of Cyprus in our sample, none of our findings would be altered significantly if we attributed a smaller trade deficit to Cyprus.
} 
ances to arise (and change) endogenously in a fully dynamic model. Our model is only designed to explore the determinants of GDP levels across countries - the primary focus of this paper.

In the following, we will continue to focus on the impact of our counterfactuals on countries' real per-capita GDPs. To this end, and in order to sidestep the question how changes in trade linkages might affect trade imbalances, we perform all subsequent counterfactuals against the baseline of a world of balanced trade. That is, in Section 4.2.2, we first balance trade flows as described in this section, then introduce a further change in the international environment and report real-GDP changes relative to their balanced-trade levels. Since actual and balanced-trade GDPs are very similar for most countries, starting from a balanced-trade baseline is unlikely to have a significant effect on the findings reported below. Table 9 provides further support for this assertion: it reports the variance of log per-worker real GDPs across countries under counterfactually balanced trade. At .403, the difference between the counterfactual and actual variance (which equals .401) is almost imperceptible.

\section{[Insert Table 9 here]}

\subsubsection{Autarky}

We now turn to the question how severing all international value-added linkages would affect countries' incomes, and international income differences. We start from the baseline of balanced trade and explore the effect of imposing autarky in all countries $\left(\tau_{n^{\prime} n} \rightarrow \infty\right.$ for all $\left.n^{\prime} \neq n\right)$. Since our model permits a simple gravity representation of value-added trade flows, the real GDP change resulting from autarky relative to the balanced-trade baseline can be calculated using the formula of Arkolakis et al. $(2012)::^{27}$

$$
\ln \frac{y_{n}^{\text {autarky }}}{y_{n}^{\text {bal.trade }}}=\frac{1}{\theta} \ln v_{n n}^{\text {bal.trade }} .
$$

The bars in Figure 11 represent the real-GDP changes experienced by countries as a result of a move to autarky. Unlike the adjustment to balanced trade, a move to autarky has a negative and economically significant effect on the GDPs of all countries, ranging from $-17.5 \%$ (Luxembourg) to $-2.5 \%$ (United States). The median and mean changes are $-7.5 \%$ and $-8.3 \%$, respectively. However, while global autarky would reduce international income differences, Table 9 reports that $\operatorname{Var}\left(\ln y_{n}\right)$ falls only modestly from .403 to .393. The ratio of the 90th-percentile and 10th-percentile per-worker real GDP $\left(y_{n}^{90} / y_{n}^{10}\right)$ is barely affected.

\section{[Insert Figure 11 here]}

\footnotetext{
${ }^{27}$ See Ossa (2015) for a many-industry generalisation of Arkolakis et al. (2012).
} 
Waugh (2010) performs a similar exercise on a more heterogeneous sample of 77 countries using data from 1996. He finds an average $10.5 \%$ decline in real GDPs as a result of counterfactual global autarky, coupled with a modest effect on $\operatorname{Var}\left(\ln y_{n}\right)$ and $y_{n}^{90} / y_{n}^{10}{ }^{28}$ This is broadly consistent with the result presented here.

It may appear puzzling that our open-economy development accounting framework enables us to explain international income differences better than its traditional closed-economy counterparts, yet predicts only a modest decline in these differences if all countries were closed. The reason is that our exercise implies a different thought experiment from typical autarky counterfactuals: instead of asking what income differences would be if all countries were closed, it asks how much smaller income differences would be if all countries faced the same relative prices and bilateral trade determinants. Figure 12 illustrates this point. The figure plots real-GDP changes as a result of autarky against the log difference between countries' "relative factor cost" term and the U.S. relative factor cost. It shows that there is no robust correlation between the two: countries with low relative factor costs - which would benefit especially from attaining relative prices and bilateral trade determinants comparable to those of the U.S. - do not experience systematically smaller income losses from autarky than countries with high relative factor costs. As a result, measuring and accounting for differences in relative factor costs can help explain a sizeable portion of international income differences, even though global autarky would not reduce international income differences by much.

\section{[Insert Figure 12 here]}

\section{Conclusion}

Allowing for international trade linkages in an otherwise standard development accounting framework enables us to paint a more complete picture of the sources of international income differences. Our exercise unpacks part of the uncomfortably large black box of "residual" TFP differences between countries, which constitutes a key finding of earlier development accounting studies under the implicit assumption that countries are autarkic. It shows that relative factor costs have an important role to play in explaining why some countries are richer than others. Differences in relative factor costs, in turn, arise because countries differ in their international linkages with other markets: countries which import value added from relatively cheap sources but sell their own exports to large markets will enjoy relatively high factor costs. In this way relative factor costs encapsulate the effect on a country's income, via its

\footnotetext{
${ }^{28}$ Waugh (2010) reports a slight increase in $\operatorname{Var}\left(\ln y_{n}\right)$ from 1.30 to 1.35 as a result of autarky, and a decrease in $y_{n}^{90} / y_{n}^{10}$ from 25.7 to 23.5 (see Waugh, 2010: Table 4, p. 2118). By contrast, he finds large declines in both numbers under other counterfactual configurations of international trade costs.
} 
international linkages, of all other countries' factor endowments and the international distribution of aggregate expenditures.

A skeptical reader might observe that our framework reduces the need for aggregateTFP variations in explaining international income differences by introducing yet another layer of "unobservables": the catch-all bilateral trade determinants which underpin observed value-added linkages. Yet these bilateral trade determinants differ from aggregate TFP in conventional development accounting exercises in two important respects. First, their variation across country pairs can be disciplined with international-trade data. Second, such variation may not (only) reflect technology differences, but (also) differences in trade costs and preferences. The question which of these fundamental drivers of international trade is quantitatively most important continues to be central in international economics. If we accept the relevance of trade linkages as a source of income variation across countries, it should also be at the heart of future endeavours to understand international income differences. 


\begin{tabular}{|c|c|cccc|cccc|}
\hline \multicolumn{2}{|c|}{} & \multicolumn{5}{|c|}{1996} & \multicolumn{4}{c|}{2006} \\
\cline { 3 - 10 } & & $y_{n}$ & $k_{n}$ & $h_{n}$ & $t_{n}$ & $y_{n}$ & $k_{n}$ & $h_{n}$ & $t_{n}$ \\
$(2011 \mathrm{I} \$)$ & $(2011 \mathrm{I} \$)$ & & & $(2011 \mathrm{I} \$)$ & $(2011 \mathrm{I} \$)$ & \\
\hline \multirow{2}{*}{ Main } & Mean & 48,122 & 145,399 & 2.8 & .001 & 61,032 & 172,575 & 3.0 & -.000 \\
Sample & St. Dev. & 23,965 & 78,935 & 0.4 & .003 & 26,898 & 88,545 & 0.4 & .010 \\
& Min. & 4,525 & 8,325 & 1.8 & -.011 & 7,034 & 13,633 & 2.0 & -.019 \\
& Max. & 102,302 & 304,323 & 3.5 & .010 & 120,815 & 366,606 & 3.6 & .051 \\
& Obs. & 40 & 40 & 40 & 40 & 40 & 40 & 40 & 40 \\
\hline \multirow{2}{*}{ RoW } & & 14,492 & 36,900 & 2.0 & .043 & 18,701 & 39,745 & 2.2 & .012 \\
\hline
\end{tabular}

Table 1: Per-capita GDPs, factor endowments and transfers - summary statistics

\begin{tabular}{|c|c|c|}
\hline & $D$ & $\begin{array}{c}L \\
(\theta \rightarrow 0)\end{array}$ \\
\hline $\operatorname{Var}\left(\ln y_{n}\right)$ & .501 & .501 \\
\hline $\operatorname{Var}\left(\ln y_{n}^{E \cdot}\right)$ & .130 & .244 \\
\hline $\operatorname{Var}\left(\ln A_{n}^{E \cdot}\right)$ & .162 & .070 \\
\hline success & .26 & .49 \\
\hline ignorance & .32 & .14 \\
\hline \multicolumn{2}{|c|}{1996}
\end{tabular}

\begin{tabular}{|c|c|c|}
\hline & $D$ & $\begin{array}{c}L \\
(\theta \rightarrow 0)\end{array}$ \\
\hline $\operatorname{Var}\left(\ln y_{n}\right)$ & .401 & .401 \\
\hline $\operatorname{Var}\left(\ln y_{n}^{E \cdot}\right)$ & .101 & .200 \\
\hline $\operatorname{Var}\left(\ln A_{n}^{E \cdot}\right)$ & .113 & .046 \\
\hline success & .25 & .50 \\
\hline ignorance & .28 & .11 \\
\hline \multicolumn{3}{|c|}{2006}
\end{tabular}

Table 2: Development accounting - without and with value-added linkages

\begin{tabular}{|c|c|c|c|c|}
\hline & $D$ & $\begin{array}{c}L \\
(\theta \rightarrow 0)\end{array}$ & $\begin{array}{c}L \\
(\theta=1.8)\end{array}$ & $\begin{array}{c}L \\
(\theta=4.0)\end{array}$ \\
\hline $\operatorname{Var}\left(\ln y_{n}\right)$ & .401 & .401 & .401 & .401 \\
\hline $\operatorname{Var}\left(\ln y_{n}^{E \cdot}\right)$ & .101 & .200 & .375 & .614 \\
\hline $\operatorname{Var}\left(\ln A_{n}^{E \cdot}\right)$ & .113 & .046 & .014 & .041 \\
\hline success & .25 & .50 & .94 & 1.53 \\
\hline ignorance & .28 & .11 & .03 & .10 \\
\hline
\end{tabular}

Table 3: Development accounting - different values of $\theta$ 


\begin{tabular}{|c|c|c|c|c|}
\hline & $D$ & $\begin{array}{c}L \\
(\theta \rightarrow 0)\end{array}$ & $\begin{array}{c}L \\
(\theta=1.8)\end{array}$ & $\begin{array}{c}L \\
(\theta=4.0)\end{array}$ \\
\hline $\operatorname{Var}\left(\ln y_{n}\right)$ & .401 & .401 & .401 & .401 \\
\hline $\operatorname{Var}\left(\ln y_{n}^{E \cdot}\right)$ & .415 & .321 & .498 & .717 \\
\hline $\operatorname{Var}\left(\ln A_{n}^{E \cdot}\right)$ & .558 & .301 & .087 & .080 \\
\hline success & 1.03 & .80 & 1.24 & 1.79 \\
\hline ignorance & 1.39 & .75 & .22 & .20 \\
\hline
\end{tabular}

Table 4: Development accounting with country-specific labour shares - different values of $\theta$

\begin{tabular}{|c|c|c|c|c|}
\hline \multicolumn{2}{|c|}{} & \multicolumn{3}{|c|}{2006} \\
\cline { 3 - 5 } & & PWT & \multicolumn{2}{|c|}{ Model $(\theta=4.0)$} \\
\cline { 3 - 5 } \multicolumn{2}{|c|}{} & $\ln G_{n}$ & $\ln F_{n}$ & $\ln G_{n}$ \\
\hline Main & Mean & .0468 & -.3594 & .0841 \\
Sample & St. Dev. & .0815 & .4926 & .0339 \\
& Min. & -.0790 & -1.8429 & .0279 \\
& Max. & .4068 & .1074 & .1560 \\
& Obs. & 40 & 40 & 40 \\
\hline RoW & & .0028 & -.9468 & .0803 \\
\hline
\end{tabular}

Table 5: "Relative factor costs" and $R G D P^{e} / R G D P^{o}$ "gaps" - summary statistics

\begin{tabular}{|c|c|c|lc|}
\hline \multicolumn{2}{|c|}{} & \multicolumn{3}{|c|}{2006} \\
\cline { 3 - 5 } Correlation & PWT & \multicolumn{1}{|c|}{ Model $(\theta=4.0)$} \\
\cline { 3 - 5 } \multicolumn{2}{|c|}{} & $\ln G_{n}$ & $\ln F_{n}$ & $\ln G_{n}$ \\
\hline \multirow{2}{*}{ PWT } & $\ln G_{n}$ & 1.00 & \\
\hline \multirow{2}{*}{ Model } & $\ln F_{n}$ & .18 & 1.00 \\
$(\theta=4.0)$ & & $(.26)$ & & \\
& $\ln G_{n}$ & $.52^{* * *}$ & .03 & 1.00 \\
& & $(.00)$ & $(.85)$ & \\
\hline
\end{tabular}

(significance levels from $t$-tests of the Pearson product-moment correlation coefficient in parentheses, $\left.{ }^{*} p<.1,{ }^{* *} p<.05,{ }^{* * *} p<.01\right)$

Table 6: "Relative factor costs" and $R G D P^{e} / R G D P^{o}$ "gaps" - correlations 


\begin{tabular}{|c|c|c|c|}
\hline \multirow{2}{*}{} & $D$ & \multicolumn{2}{|c|}{$\ln G_{n}$} \\
\cline { 2 - 4 } & & PWT & $\begin{array}{c}\text { Model } \\
(\theta=4.0)\end{array}$ \\
\hline $\operatorname{Var}\left(\ln y_{n}\right)$ & .401 & .401 & .401 \\
\hline $\operatorname{Var}\left(\ln y_{n}^{E \cdot}\right)$ & .101 & .121 & .107 \\
\hline $\operatorname{Var}\left(\ln A_{n}^{E \cdot}\right)$ & .113 & .106 & .111 \\
\hline success & .25 & .30 & .27 \\
\hline ignorance & .28 & .26 & .28 \\
\hline
\end{tabular}

2006

Table 7: Development accounting with "gaps"

\begin{tabular}{|c|c|ccc|cc|}
\hline & & $\begin{array}{c}\gamma_{n^{\prime} n} \\
\left(n^{\prime} \neq n\right)\end{array}$ & $\gamma_{n n}$ & $A_{n}$ & $\theta$ & $\alpha$ \\
& & & & & & \\
& & & & & \\
\hline$n \in$ & Mean & .014 & .432 & 717 & & \\
Main & St. Dev. & .040 & .363 & 159 & \\
Sample & Min. & .000 & .001 & 487 & \\
& Max. & .625 & .969 & 1178 & \\
& Obs. & 1,600 & 40 & 40 & \\
\hline \multirow{2}{*}{$n=$} & Mean & .025 & .016 & 827 & \\
& St. Dev. & .068 & 0 & 0 & \\
& Min. & .000 & .016 & 827 & \\
& Max. & .417 & .016 & 827 & \\
& Obs. & 40 & 1 & 1 & \\
\hline
\end{tabular}

Table 8: Parameter calibration for 2006 counterfactuals

\begin{tabular}{|c|c|l|c|c|}
\hline \multicolumn{2}{|c|}{ Data } & \multicolumn{3}{c|}{ Model } \\
\hline $\operatorname{Var}\left(\ln y_{n}\right)$ & $y_{n}^{90} / y_{n}^{10}$ & Scenario & $\operatorname{Var}\left(\ln y_{n}\right)$ & $y_{n}^{90} / y_{n}^{10}$ \\
\hline .401 & 4.00 & Baseline & .401 & 4.00 \\
& & Balanced Trade & .403 & 4.04 \\
& & Autarky & .393 & 4.01 \\
\hline
\end{tabular}

Table 9: Income differences - counterfactual scenarios 


\begin{tabular}{|c|c|c|c|c|c|}
\hline Source & $\begin{array}{c}\text { Data } \\
\text { Construction }\end{array}$ & & $D$ & $\begin{array}{c}L \\
(\theta \rightarrow 0)\end{array}$ & $\begin{array}{c}L \\
(\theta=4)\end{array}$ \\
\hline \multirow{4}{*}{ PWT 9.0} & Caselli & success & .26 & .49 & 1.59 \\
\hline & $(2005)$ & ignorance & .32 & .14 & .16 \\
\hline & \multirow{2}{*}{ PWT } & success & .32 & .56 & 1.58 \\
\hline & & ignorance & .28 & .13 & .16 \\
\hline \multirow{4}{*}{ PWT 8.1} & Caselli & success & .25 & .48 & 1.63 \\
\hline & $(2005)$ & ignorance & .33 & .14 & .15 \\
\hline & \multirow{2}{*}{ PWT } & success & .28 & .51 & 1.63 \\
\hline & & ignorance & .31 & .13 & .15 \\
\hline \multirow{3}{*}{ PWT 7.1} & Caselli & success & .20 & .39 & 1.30 \\
\hline & $(2005)$ & ignorance & .37 & .18 & .11 \\
\hline & PWT & $\begin{array}{c}\text { success } \\
\text { ignorance }\end{array}$ & $\begin{array}{l}- \\
-\end{array}$ & - & - \\
\hline
\end{tabular}

1996

\begin{tabular}{|c|c|c|c|c|c|}
\hline Source & $\begin{array}{c}\text { Data } \\
\text { Construction }\end{array}$ & & $D$ & $\begin{array}{c}L \\
(\theta \rightarrow 0)\end{array}$ & $\begin{array}{c}L \\
(\theta=4)\end{array}$ \\
\hline \multirow{4}{*}{ PWT 9.0} & Caselli & success & .25 & .50 & 1.53 \\
\hline & $(2005)$ & ignorance & .28 & .11 & .10 \\
\hline & \multirow{2}{*}{ PWT } & success & .26 & .51 & 1.53 \\
\hline & & ignorance & .30 & .13 & .11 \\
\hline \multirow{4}{*}{ PWT 8.1} & Caselli & success & .24 & .49 & 1.54 \\
\hline & $(2005)$ & ignorance & .30 & .12 & .11 \\
\hline & \multirow{2}{*}{ PWT } & success & .24 & .48 & 1.54 \\
\hline & & ignorance & .31 & .12 & .12 \\
\hline \multirow{3}{*}{ PWT 7.1} & Caselli & success & .21 & .42 & 1.30 \\
\hline & $(2005)$ & ignorance & .32 & .14 & .06 \\
\hline & PWT & $\begin{array}{c}\text { success } \\
\text { ignorance }\end{array}$ & - & - & - \\
\hline
\end{tabular}

2006

Table 10: Robustness - different construction methods/sources for factor endowments 


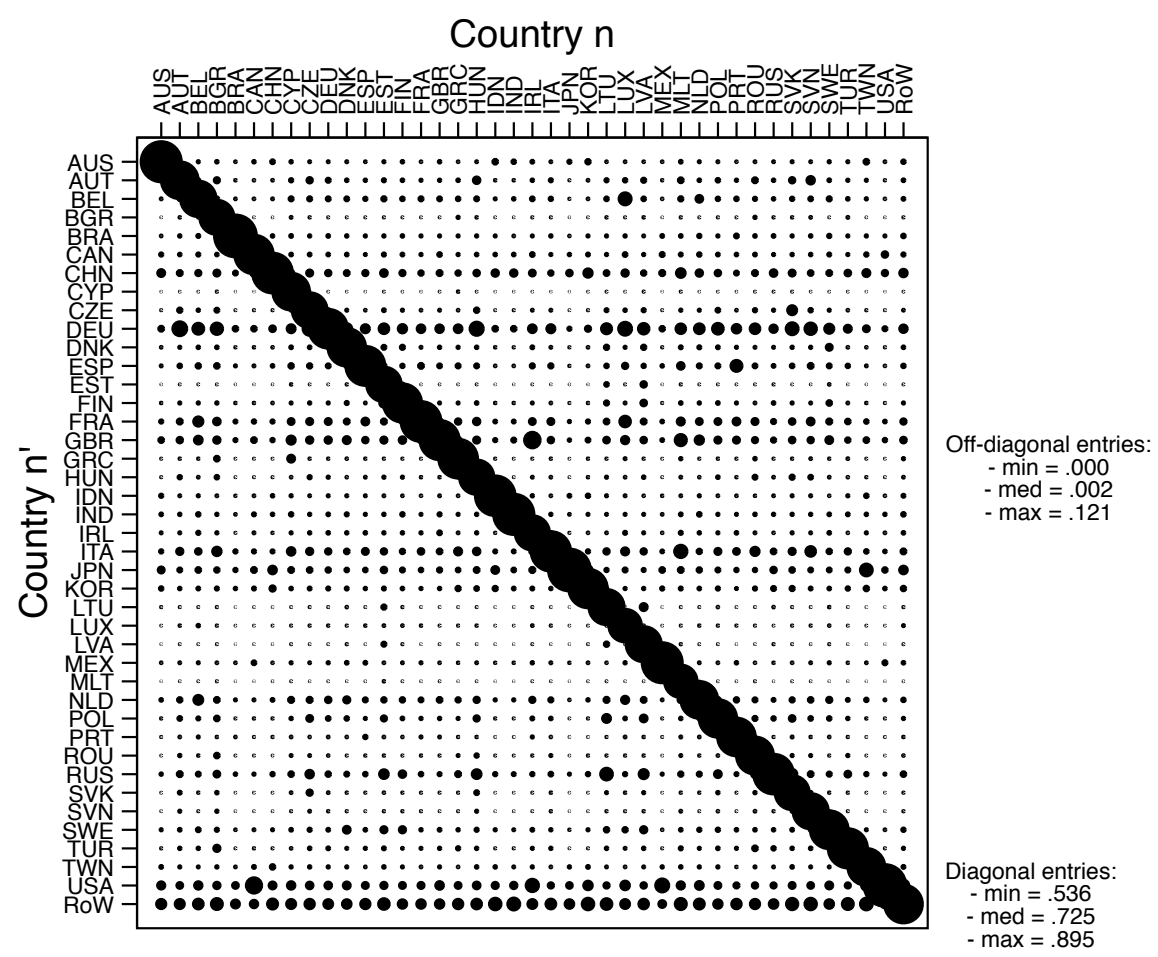

Share of country-n' value added in country-n final use ("v_n'n")

Figure 1: Matrix of international value-added linkages
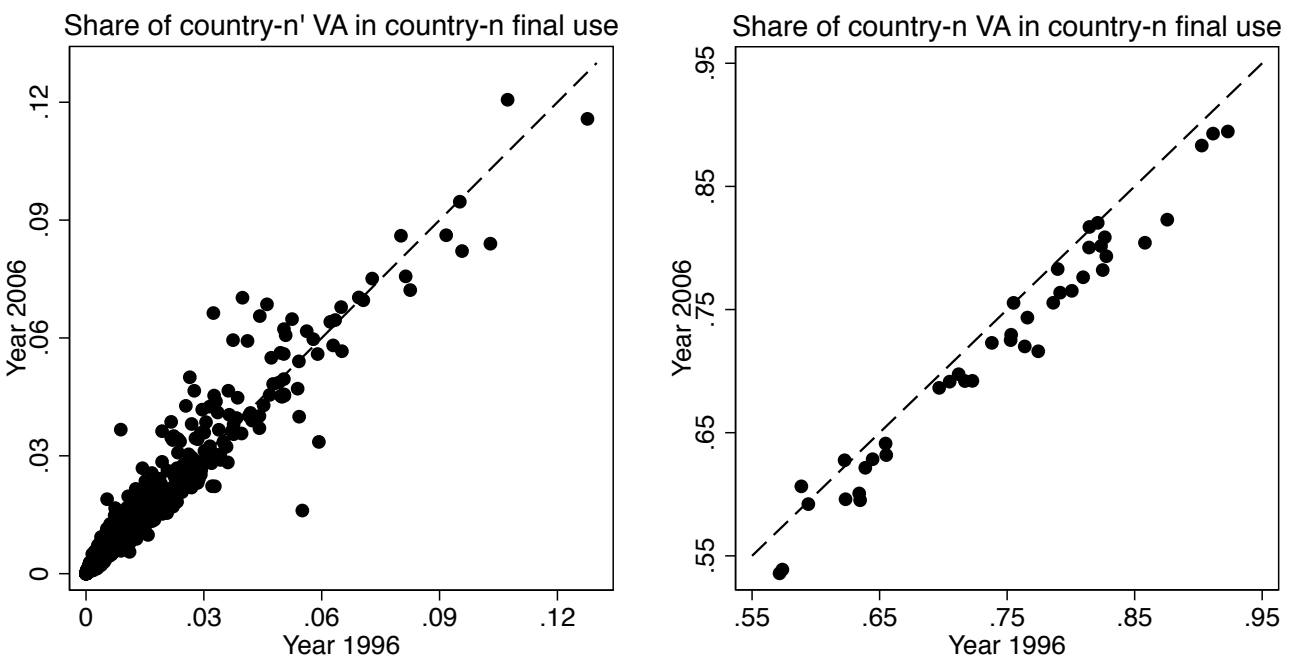

Figure 2: Change in value-added linkages over time 

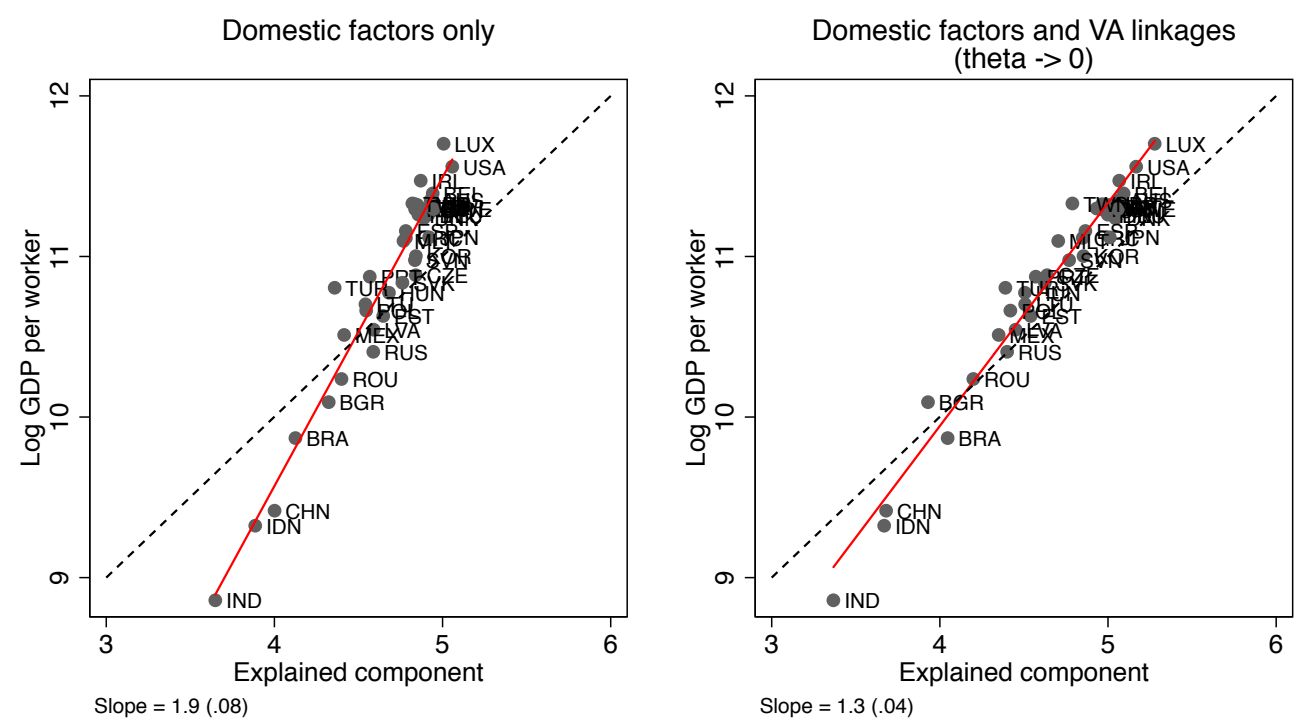

Figure 3: Explained component of log per-worker GDP

- without and with value-added linkages
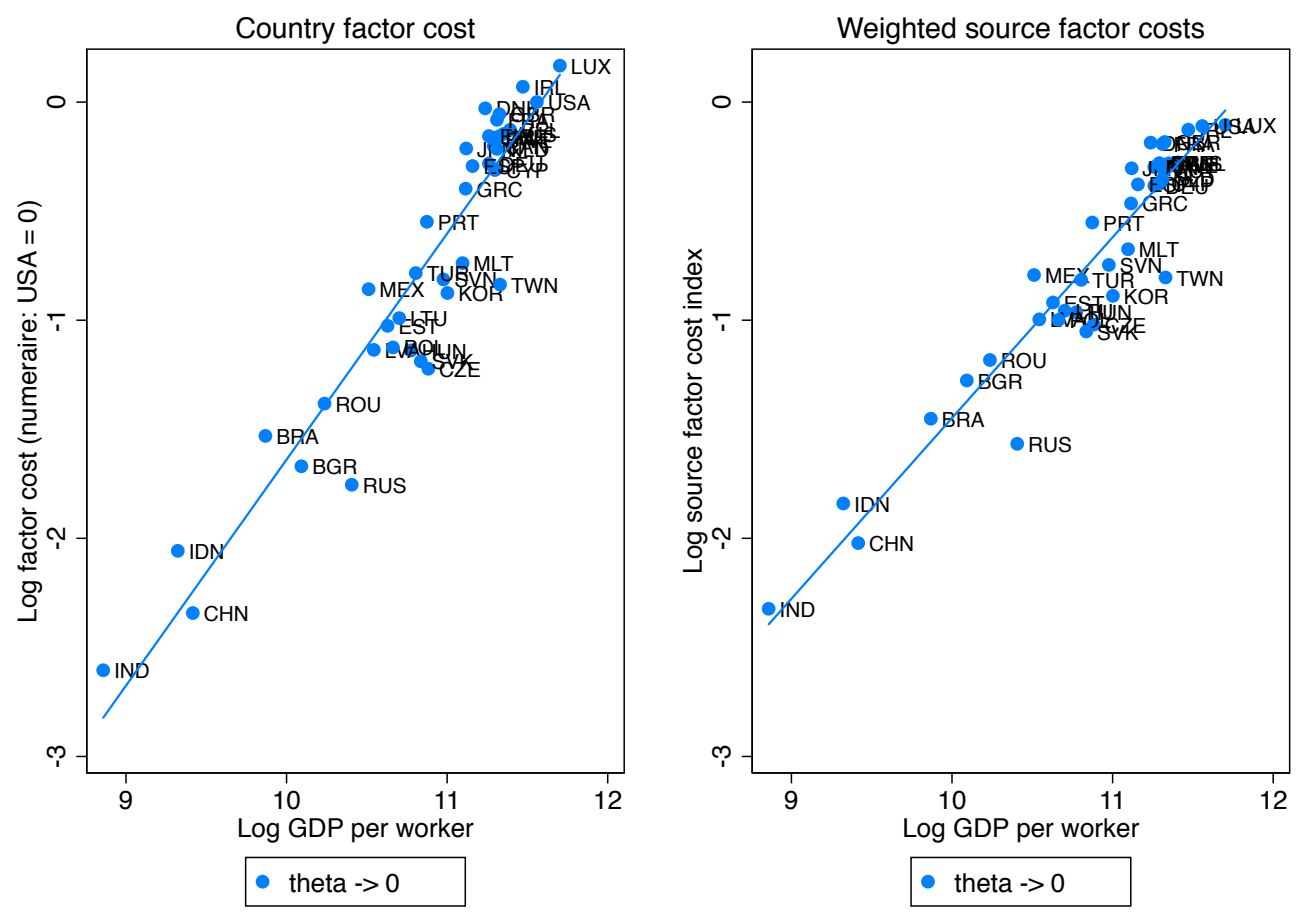

Figure 4: Correlation of model-implied home-country and weighted source factor costs with actual per-worker GDP 


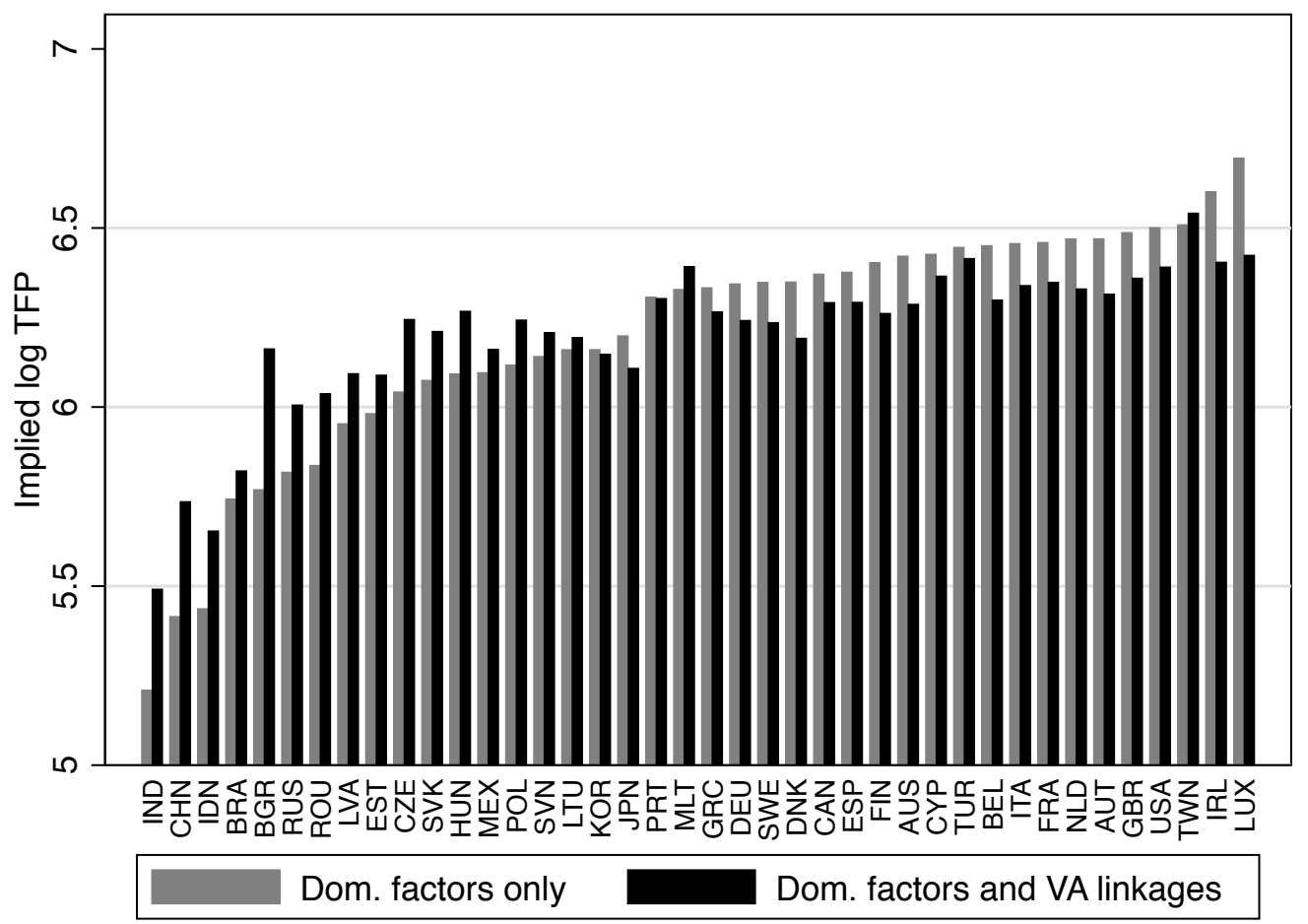

Figure 5: Implications of international value-added linkages for measured TFP $(\theta \rightarrow 0)$
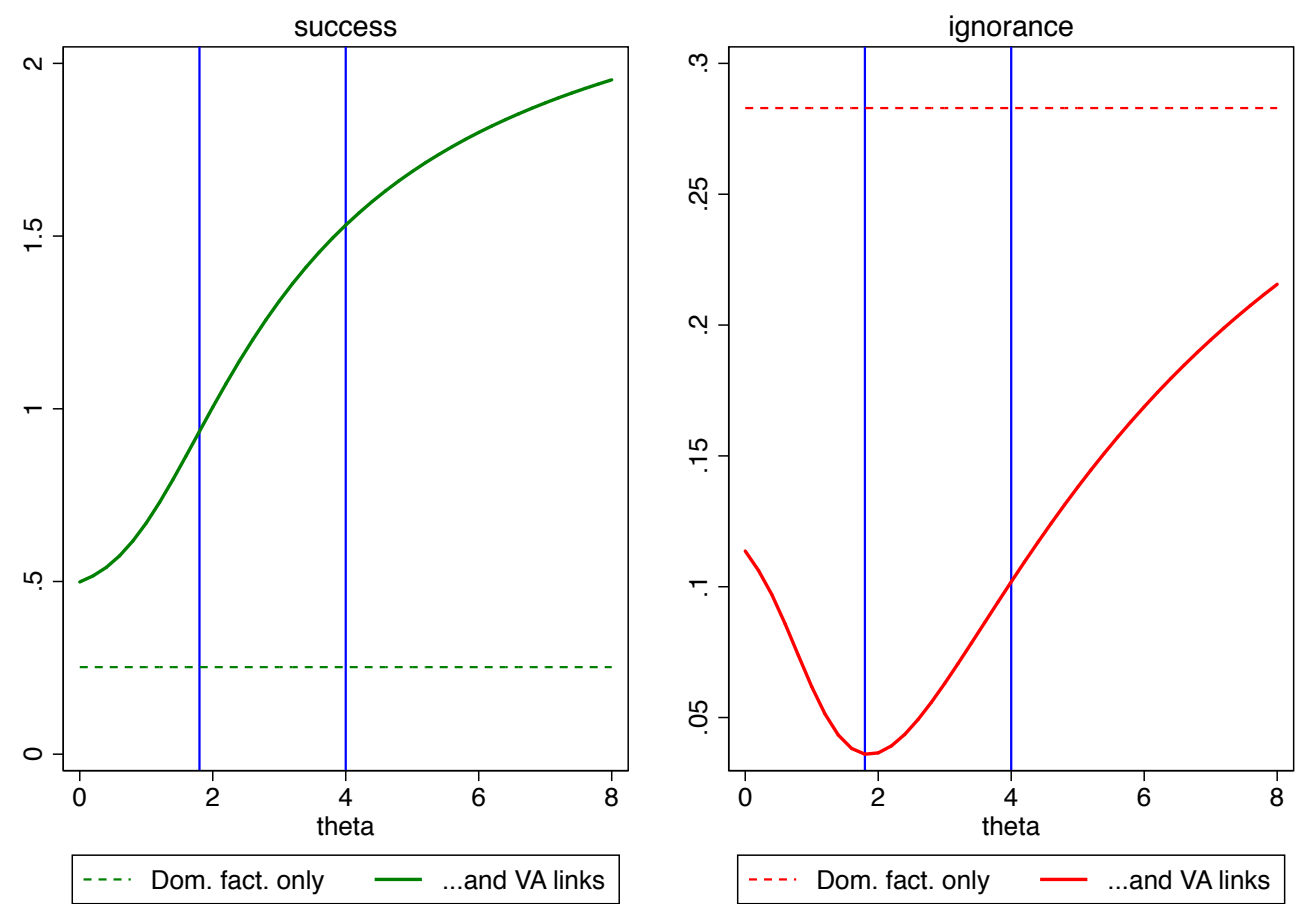

Figure 6: success and ignorance for different values of $\theta$ 

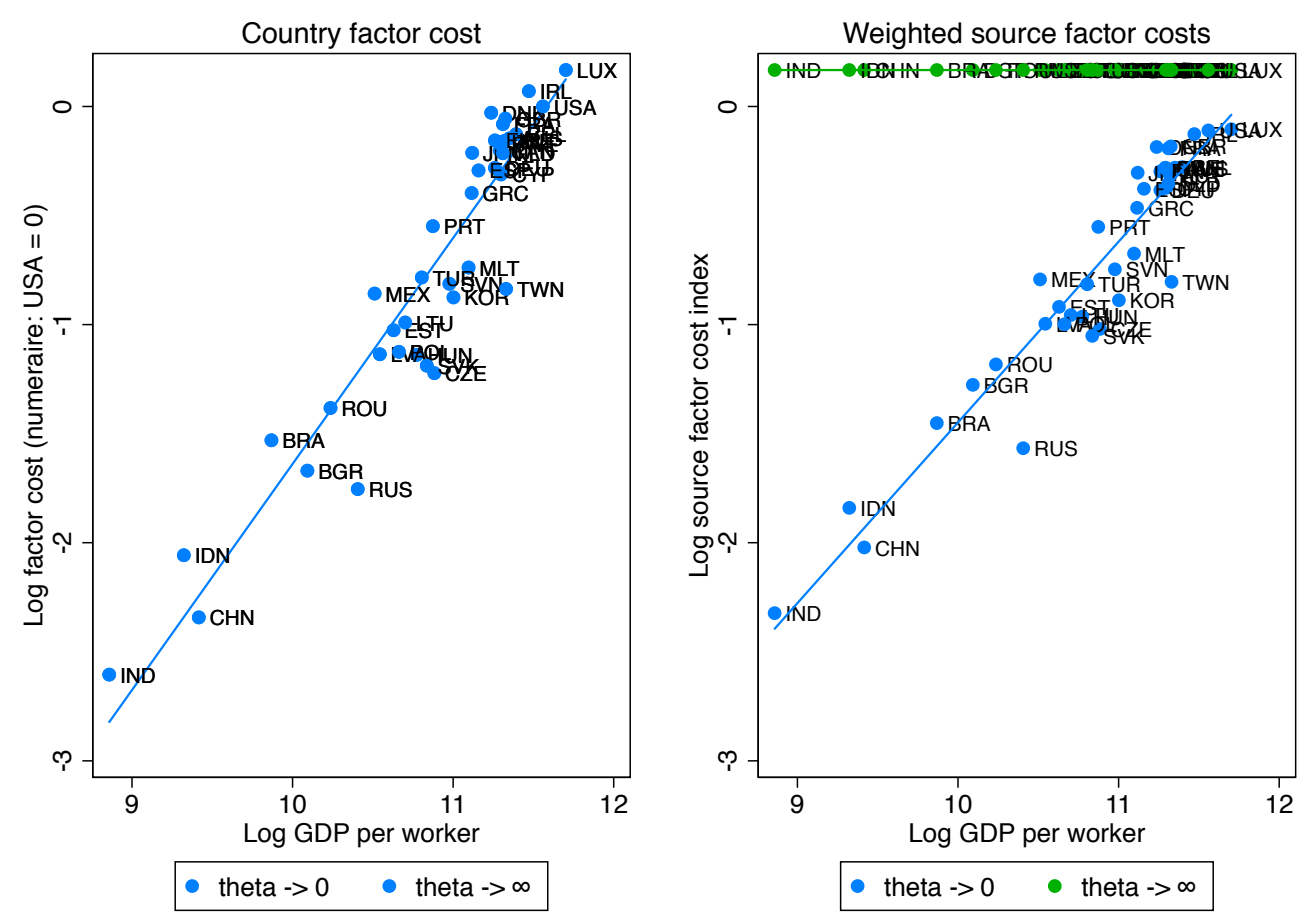

Figure 7: Correlation of model-implied home-country and weighted source factor costs with actual per-worker GDP (for $\theta \rightarrow 0$ and $\theta \rightarrow \infty$ )

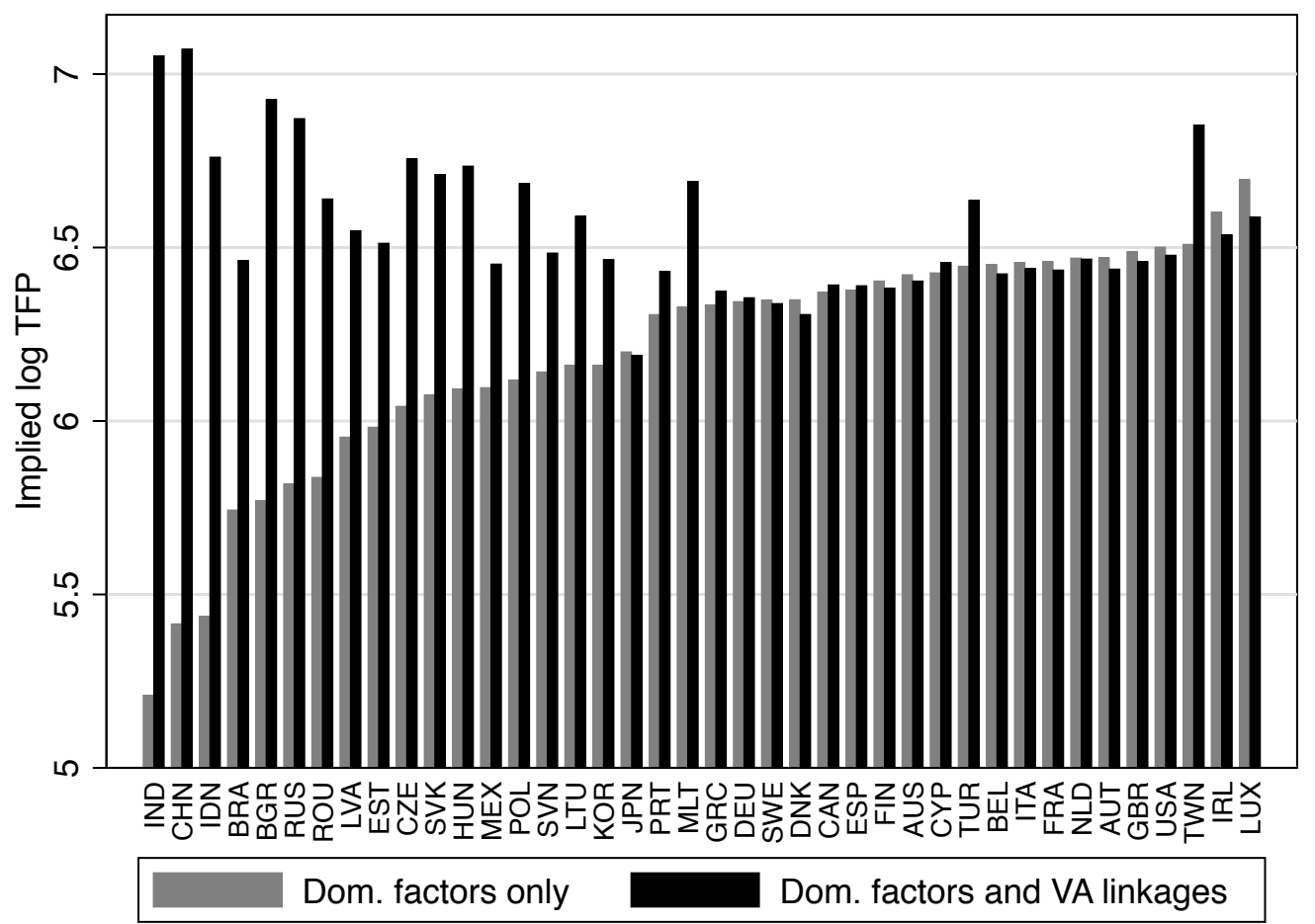

Figure 8: Implications of international value-added linkages for measured TFP $(\theta=4)$ 


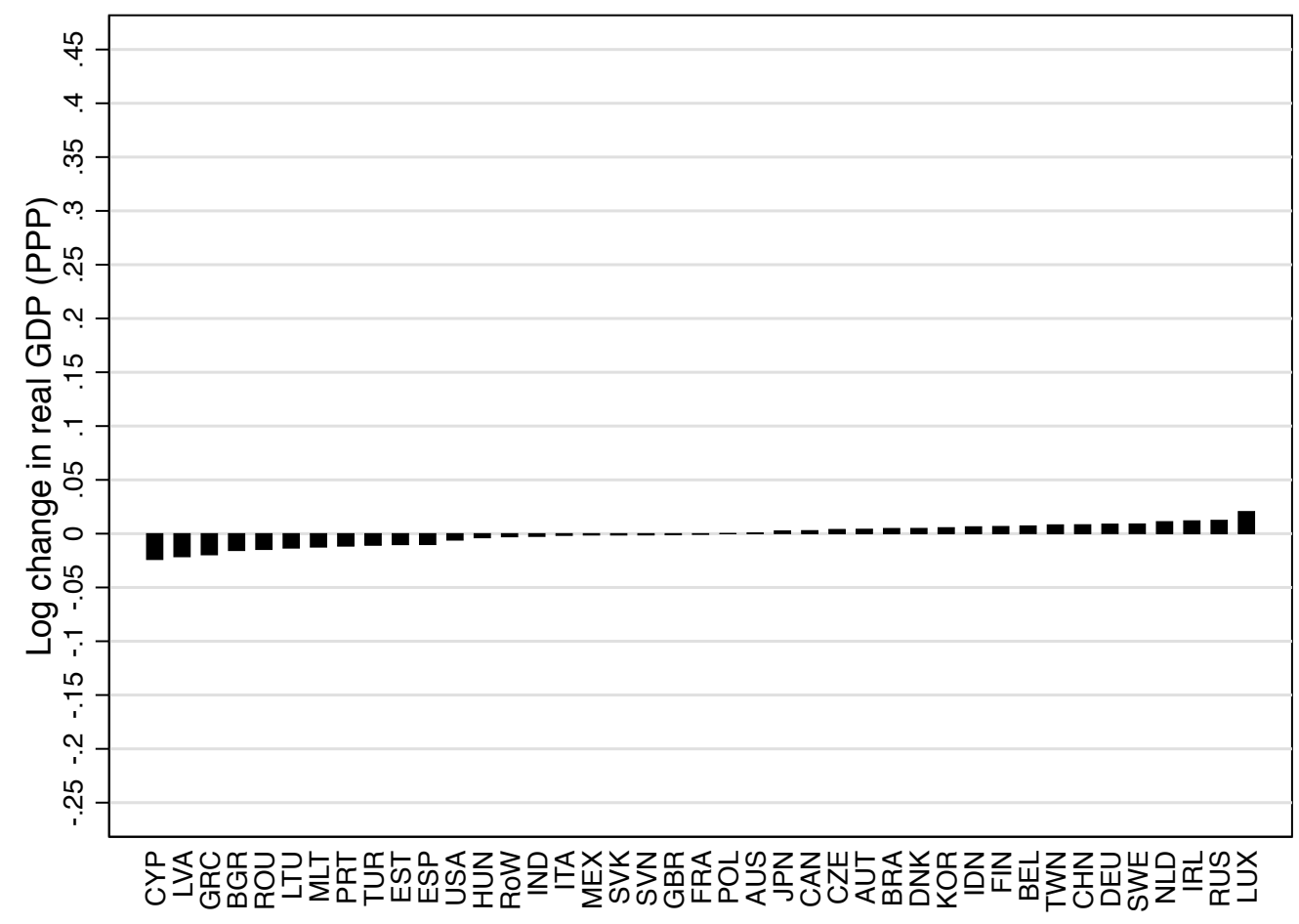

Figure 9: Balanced trade counterfactual - real GDP changes

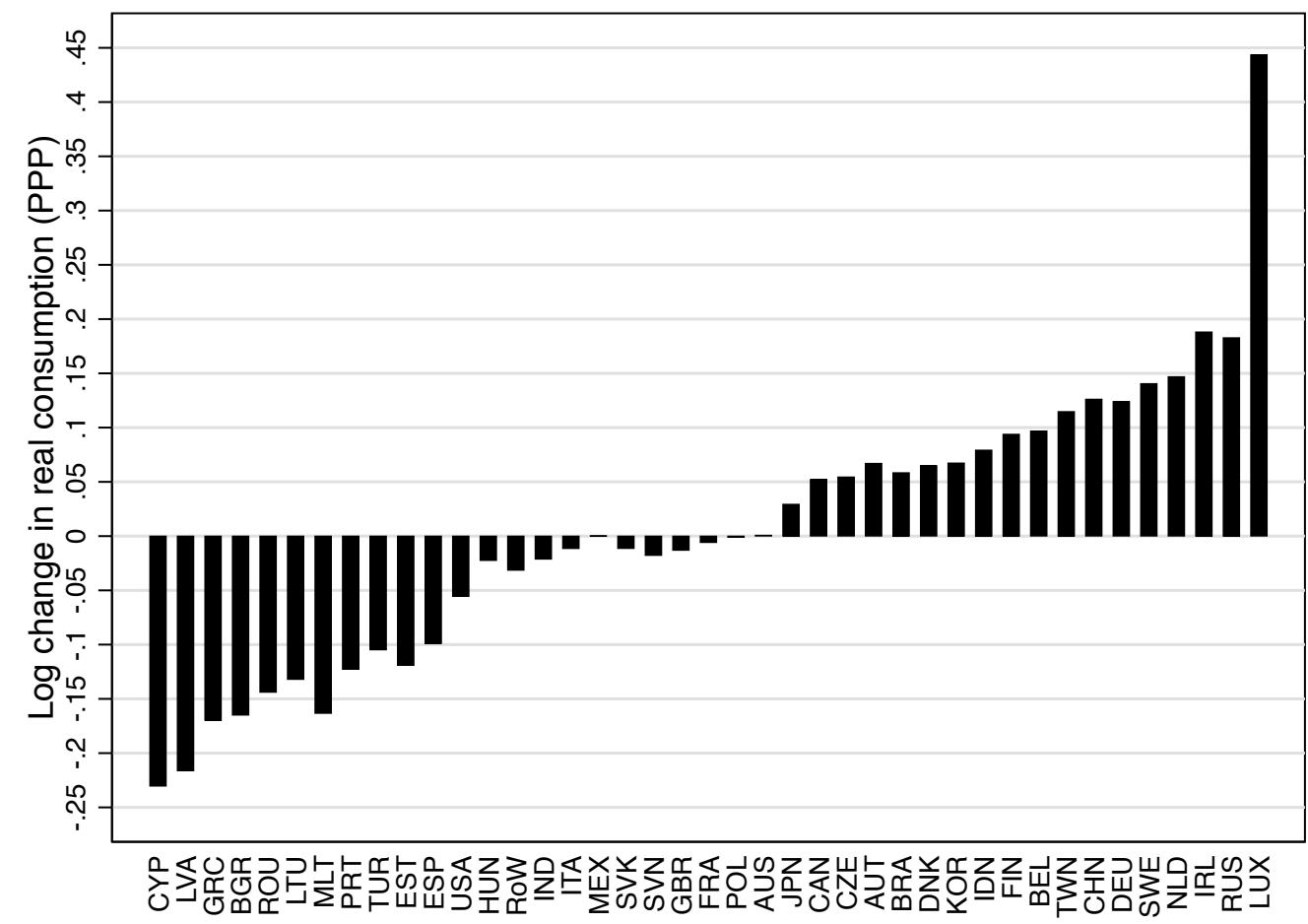

Figure 10: Balanced trade counterfactual - real consumption changes 


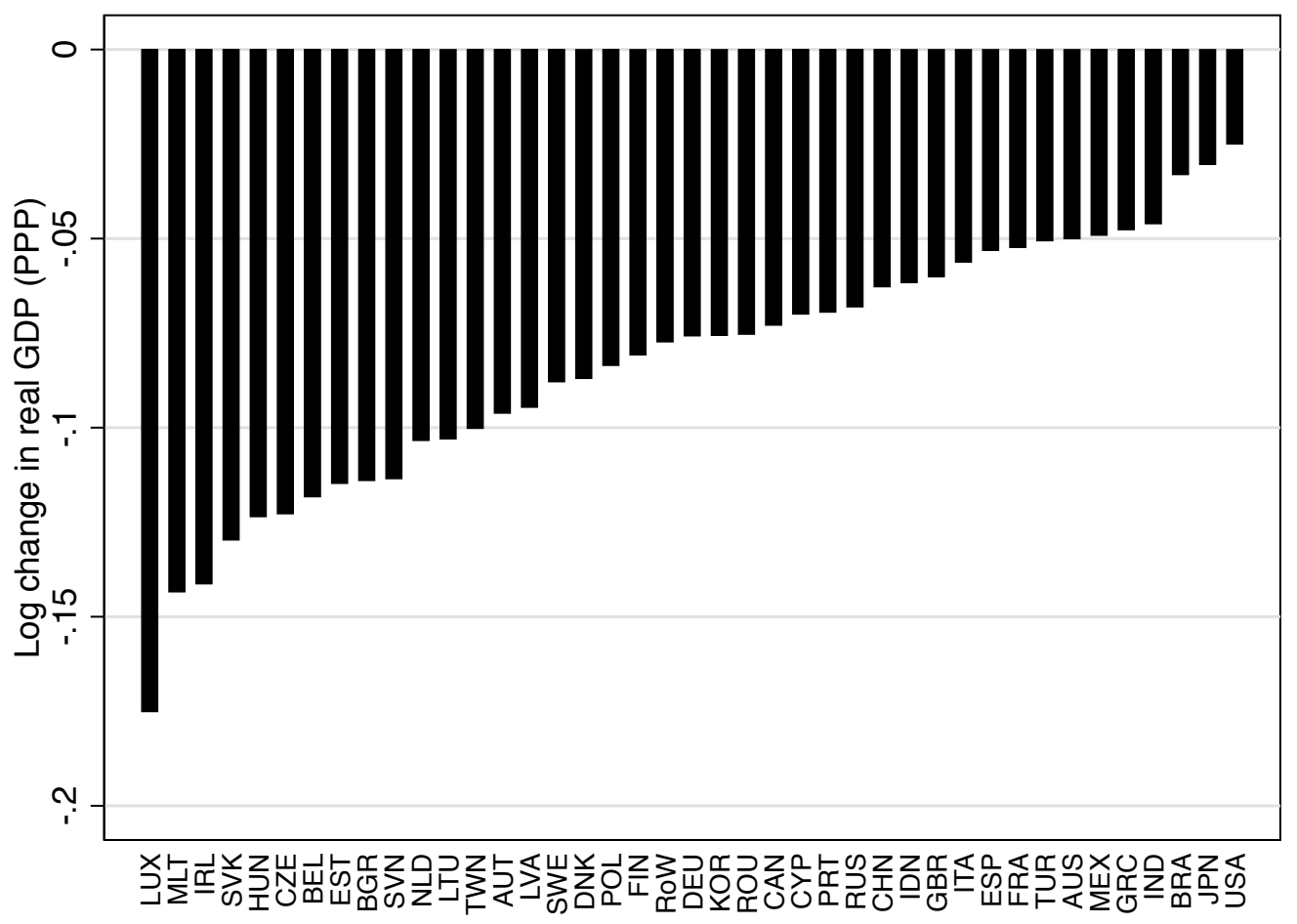

Figure 11: Autarky counterfactuals - real GDP changes

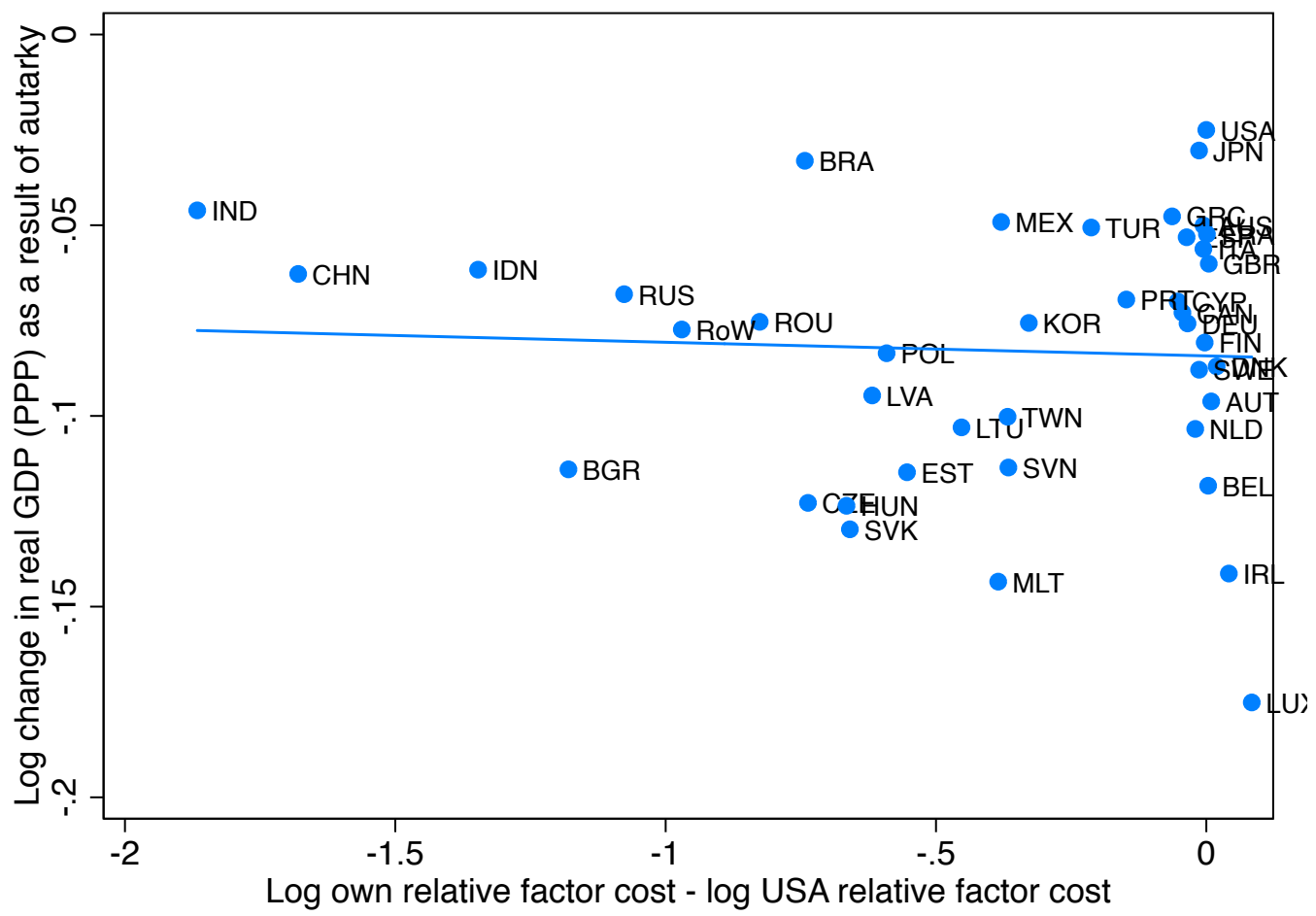

Figure 12: Losses from autarky and relative factor costs 


\section{References}

[1] Abramovitz, Moses, 1956. "Resource and Output Trends in the U.S. since 1870." American Economic Review: Papers and Proceedings, 46, 2, pp. 5-23.

[2] Arkolakis, Costas, Arnaud Costinot, and Andres Rodriguez-Clare, 2012. "New Trade Models, Same Old Gains?," American Economic Review, 102, 1, pp. 94130.

[3] Backus, David K., Patrick J. Kehoe, and Finn E. Kydland, 1994. "Dynamics of the Trade Balance and the Terms of Trade: The J-Curve?," American Economic Review, 84, 1, pp. 84-103.

[4] Barro, Robert J., and Lee, Jong Wha, 2013. "A New Data Set of Educational Attainment in the World, 1950-2010," Journal of Development Economics, 104, C, pp. 184-198.

[5] Bems, Rudolfs, 2014. "Intermediate Inputs, External Rebalancing and Relative Price Adjustment," Journal of International Economics, 94, 2, pp. 248-262.

[6] Bems, Rudolfs, Robert C. Johnson, and Kei-Mu Yi, 2011. "Vertical Linkages and the Collapse of Global Trade," American Economic Review, 101, 3, pp. 308-12.

[7] Caliendo, Lorenzo and Fernando Parro, 2015. "Estimates of the Trade and Welfare Effects of NAFTA," Review of Economic Studies, 82, 1, pp. 1-44.

[8] Caliendo, Lorenzo, Fernando Parro, and Aleh Tsyvinski, 2017. "Distortions and the Structure of the World Economy," manuscript.

[9] Caselli, Francesco, 2005. "Accounting for Cross-Country Income Differences,"Handbook of Economic Growth, in: Philippe Aghion \& Steven Durlauf (ed.), Handbook of Economic Growth, edition 1, volume 1, chapter 9, pp. 679-741.

[10] Caselli, Francesco, 2015. "Technology Differences Over Space and Time," manuscript.

[11] Caselli, Francesco, and Wilbur C. Coleman, 2006. "The World Technology Frontier," American Economic Review, 96, 3, pp. 499-522.

[12] Cohen, Daniel, and Laura Leker, 2014. "Health and Education: Another Look with the Proper Data", manuscript.

[13] Dekle, Robert, Jonathan Eaton, and Samuel Kortum, 2007. "Unbalanced Trade," American Economic Review, 97, 2, pp 351-355. 
[14] Dekle, Robert, Jonathan Eaton, and Samuel Kortum, 2008. "Global Rebalancing with Gravity: Measuring the Burden of Adjustment," IMF Staff Papers, 55, 3, pp. 511-540.

[15] Dornbusch, Rudiger, Stanley Fischer, and Paul Samuelson, 1977. "Comparative Advantage, Trade, and Payments in a Ricardian Model with a Continuum of Goods," American Economic Review, 67, 5, pp. 823-839.

[16] Duval, Romain, Nan Li, Richa Saraf, and Dulani Seneviratne, 2015. "Trade and Business Cycle Synchronization: Value Added is what Matters," Journal of International Economics, forthcoming.

[17] Eaton, Jonathan, and Samuel Kortum, 2002. "Technology, Geography, and Trade," Econometrica, 70, 5, pp. 1741-1779.

[18] Fadinger, Harald, 2011. "Productivity differences in an interdependent world," Journal of International Economics, 84, 2, pp. 221-232.

[19] Fadinger, Harald, Christian Ghiglino, and Mariya Teteryatnikova, 2015. "Income Differences and Input-Output Structure," WP 15-11, University of Mannheim.

[20] Feenstra, Robert C., Alan Heston, Marcel P. Timmer, and Haiyan Deng, 2009. "Estimating Real Production and Expenditures Across Nations: A Proposal for Improving the Penn World Tables," Review of Economics and Statistics, 91, 1, pp. 201-212.

[21] Feenstra, Robert C., and John Romalis, 2014. "International Prices and Endogenous Quality," Quarterly Journal of Economics, 129, 2, pp. 477-527.

[22] Feenstra, Robert C., Robert Inklaar, and Marcel P. Timmer, 2015. "The Next Generation of the Penn World Table," American Economic Review, 105, 10, pp. 3150-3182.

[23] Gollin, Douglas, 2002. "Getting Income Shares Right," Journal of Political Economy, 110, 2, pp. 458-474.

[24] Grobovšek, Jan, 2015. "Development Accounting with Intermediate Goods," manuscript, University of Edinburgh.

[25] Hall, Robert E., and Charles I. Jones, 1999. "Why do Some Countries Produce So Much More Output Per Worker than Others?," Quarterly Journal of Economics, 114, 1, pp. 83-116.

[26] Harris, Chauncy D., 1954. "The Market as a Factor in the Localization of Industry in the United States," Annals of the Association of American Geographers, 44, 4, pp. 315-348. 
[27] Hsieh, Chang-Tai, and Peter J.Klenow, 2010. "Development Accounting," American Economic Journal: Macroeconomics, 2, 1, pp. 207-223.

[28] Hummels, David L., Jun Ishii, and Kei-Mu Yi, 2001. "The Nature and Growth of Vertical Specialization in World Trade," Journal of International Economics, 54,1 , pp. 75-96.

[29] Inklaar, Robert, and Marcel P. Timmer, 2013. "Capital, Labor and TFP in PWT 8.0 ", manuscript.

[30] Inklaar, Robert, and Marcel P. Timmer, 2016. "Human Capital in PWT 9.0", manuscript.

[31] Johnson, Robert C., 2014. "Trade in Intermediate Inputs and Business Cycle Comovement," American Economic Journal: Macroeconomics, 6, 4, pp. 39-84.

[32] Johnson, Robert C., and Guillermo Noguera, 2012. "Accounting for Intermediates: Production Sharing and Trade in Value Added," Journal of International Economics, 86, 2, pp. 224-236.

[33] Jones, Charles I., 2011. "Intermediate Goods and Weak Links in the Theory of Economic Development," American Economic Journal: Macroeconomics, 3, 2, pp. 1-28.

[34] Jones, Charles I., 2015. "The Facts of Economic Growth," NBER WP 21142.

[35] Karabarbounis, Loukas, and Brent Neiman, 2014. "The Global Decline of the Labor Share," Quarterly Journal of Economics, 129, 1, pp. 61-103.

[36] Kehoe, Timothy J., and Kim J. Ruhl, 2008. "Are Shocks to the Terms of Trade Shocks to Productivity?" Review of Economic Dynamics, 11, 4, pp. 804-819.

[37] Keynes, John Maynard, "The German Transfer Problem," "The Reparation Problem: A Discussion. II. A Rejoinder," "Views on The Transfer Problem. III. A Reply," Economic Journal 39 (March 1929), pp. 1-7, (June 1929), pp. 172-178, (Sept. 1929), pp. 404-408.

[38] Klenow, Pete, and Andrés Rodríguez Clare, 1997. "The Neoclassical Revival in Growth Economics: Has It Gone Too Far?" in B. Bernanke and J. Rotemberg (eds.) NBER Macroeconomics Annual 1997, Cambridge, MIT Press, pp. 73-102.

[39] Kose, M. Ayhan, and Kei-Mu Yi, 2001. "International Trade and Business Cycles: Is Vertical Specialization the Missing Link?," American Economic Review, 91, 2, pp. 371-375. 
[40] Leontief, Wassily, 1936. "Quantitative Input and Output Relations in the Economic System of the United States," Review of Economic Statistics, 18, 3, pp. $105-125$.

[41] Malmberg, Hannes, 2016. "Human Capital and Development Accounting Revisited," manuscript.

[42] Morrow, Peter M., and Daniel Trefler, 2014. "HOV and the Factor Bias of Technology," manuscript.

[43] Ohlin, Bertil, "The Reparation Problem: A Discussion. I. Transfer Difficulties, Real and Imagined", "Mr. Keynes' Views on the Transfer Problem. II. A Rejoinder," Economic Journal 39 (June 1929), pp. 172-182, (Sept. 1929), pp. 400-404.

[44] Ossa, Ralph, 2015. "Why Trade Matters After All," Journal of International Economics, 97, 2, 266-277

[45] Redding, Stephen J., and Anthony J. Venables, 2004. "Economic Geography and International Inequality," Journal of International Economics, 62, 1, pp. 53-82.

[46] Simonovska, Ina, and Michael E. Waugh, 2014. "The Elasticity of Trade: Estimates and Evidence," Journal of International Economics, 92, 1, pp. 34-50.

[47] Timmer, Marcel P., Erik Dietzenbacher, Bart Los, Robert Stehrer, and Gaaitzen J. de Vries, 2013. "Fragmentation, Incomes and Jobs: an Analysis of European Competitiveness," Economic Policy, 28, 76, pp. 613-661.

[48] Timmer, Marcel P., Erik Dietzenbacher, Bart Los, Robert Stehrer, and Gaaitzen J. de Vries, 2015. "An Illustrated User Guide to the World Input-Output Database: the Case of Global Automotive Production," Review of International Economics, 23, pp. 575-605.

[49] Trefler, Daniel, 1993. "International Factor Price Differences: Leontief Was Right!" Journal of Political Economy, 101, 6, pp. 961-987.

[50] Waugh, Michael E., 2010. "International Trade and Income Differences," American Economic Review, 100, 5, pp. 2093-2124.

[51] Yi, Kei-Mu, 2003. "Can Vertical Specialization Explain the Growth of World Trade?," Journal of Political Economy, 111, 1, pp. 52-102.

[52] Yi, Kei-Mu, 2010. "Can Multistage Production Explain the Home Bias in Trade?," American Economic Review, 100, 1, pp. 364-393. 


\section{A Appendix}

\section{A.1 An Isomorphic Eaton-Kortum Model}

This section presents a Ricardian model with input-output linkages based on Eaton and Kortum (2002), which has the same implications in terms of value-added outcomes as the Armington model of Section 2.

\section{A.1.1 Preferences, Technologies and Market Structure}

There are many countries, $n=1, \ldots, N$, trading in a continuum of goods, $i \in[0,1]$. The representative consumer in $n$ purchases goods in amounts $c_{n}(i)$ to maximise

$$
C_{n}=A_{n}\left[\int_{0}^{1} c_{n}(i)^{\frac{\sigma-1}{\sigma}} d i\right]^{\frac{\sigma}{\sigma-1}}
$$

$\sigma \geq 0$. The maximisation is subject to a budget constraint which is analogous to equation (2):

$$
\int_{0}^{1} p_{n}(i) c_{n}(i) d i \leq r_{n} K_{n}+w_{n} L_{n}+T_{n} .
$$

Country $n^{\prime}$ can produce goods for $n$ using the following country-pair-good-specific production technology:

$$
q_{n^{\prime} n}(i)=Z_{n^{\prime} n}(i)\left\{\left(1-\beta_{n}\right)^{\frac{1}{\varepsilon}}\left[K_{n^{\prime} n}(i)^{\alpha} H_{n^{\prime} n}(i)^{1-\alpha}\right]^{\frac{\varepsilon-1}{\varepsilon}}+\beta_{n}^{\frac{1}{\varepsilon}} Q_{n^{\prime} n}(i)^{\frac{\varepsilon-1}{\varepsilon}}\right\}^{\frac{\varepsilon}{\varepsilon-1}}
$$

$\beta_{n} \in[0,1), \varepsilon \geq 0 . Q_{n^{\prime} n}(i)$ denotes an aggregator of goods used as intermediates by $n^{\prime}$ to produce good $i$ for country $n$, and has the same form (and price) as $C_{n^{\prime}}{ }^{29}$ The shifter $Z_{n^{\prime} n}(i)$ is a random variable, drawn independently for each $i$ from the country-pair-specific Fréchet distribution

$$
J_{n^{\prime} n}(Z)=\operatorname{Pr}\left(Z_{n^{\prime} n} \leq Z\right)=e^{-\omega_{n^{\prime} n} Z^{-\theta}}
$$

$\omega_{n^{\prime} n} \geq 0, \theta>0$. By the law of large numbers, $J_{n^{\prime} n}(Z)$ is also the fraction of goods which country $n^{\prime}$ can produce for $n$ with efficiency below $Z$. The country-pairspecific technology parameter $\omega_{n^{\prime} n}$ governs the location of the distribution from which productivities are drawn. ${ }^{30} \mathrm{~A}$ bigger $\omega_{n^{\prime} n}$ implies that a higher-productivity draw for any good $i$ produced by $n^{\prime}$ for $n$ is more likely. Parameter $\theta$, common across countries

\footnotetext{
${ }^{29}$ Note that (33) implies that countries no longer ship simply their own value added, but a combination of own value added and intermediates produced elsewhere - with the parameter $\beta_{n}$ representing the intensity of intermediate use. As a result, the value of gross-trade flows will exceed value-added trade between countries in this model.

${ }^{30}$ Eaton and Kortum (2002) assume the location parameter is country-specific only, which is a special case of (34).
} 
by assumption, determines the amount of variation within the distribution; a smaller $\theta$ implies more variability.

Goods and factor markets are perfectly competitive. We assume that goods trade is subject to iceberg transport costs: $\tau_{n^{\prime} n} \geq 1$ units of an input must be shipped from country $n^{\prime}$ for one unit to arrive in country $n .{ }^{31}$ By contrast, production factors can move freely within countries, but cannot move across borders.

\section{A.1.2 Prices}

There are constant returns to scale, so the price to country $n$ of sourcing input $i$ from country $n^{\prime}$ is $p_{n^{\prime} n}(i)=\tau_{n^{\prime} n} b_{n^{\prime}} / Z_{n^{\prime} n}(i)$, where $b_{n} \equiv\left[\left(1-\beta_{n}\right) f_{n}^{1-\varepsilon}+\beta_{n} P_{n}^{1-\varepsilon}\right]^{\frac{1}{1-\varepsilon}}$. In equilibrium consumers in $n$ will pay price $p_{n}(i)$ for good $i$ which is such that $p_{n}(i)=$ $\min \left\{p_{n^{\prime} n}(i) ; n^{\prime}=1, \ldots, N\right\}$. Following Eaton and Kortum (2002), it is straightforward to show this implies

$$
P_{n}=\frac{1}{A_{n}}\left[\int_{0}^{1} p_{n}(i)^{1-\sigma} d i\right]^{\frac{1}{1-\sigma}}=\frac{\xi}{A_{n}}\left(\sum_{n^{\prime}=1}^{N} \omega_{n^{\prime} n} \tau_{n^{\prime} n}^{-\theta} b_{n^{\prime}}^{-\theta}\right)^{-\frac{1}{\theta}}
$$

where $P_{n}$ is the cost of one unit of final consumption $C_{n}$, and $\xi$ is a constant. ${ }^{32}$ Assuming $\varepsilon=\theta+1$,

$$
P_{n}=\frac{\xi}{A_{n}}\left(\sum_{n^{\prime}=1}^{N} \gamma_{n_{n}^{\prime} n} f_{n^{\prime}}^{-\theta}\right)^{-\frac{1}{\theta}}
$$

where

$$
\begin{aligned}
& {\left[\begin{array}{ccc}
\gamma_{11} & \cdots & \gamma_{N 1} \\
\vdots & & \vdots \\
\gamma_{1 N} & \cdots & \gamma_{N N}
\end{array}\right] \equiv} \\
& \equiv\left(I-\left[\begin{array}{ccc}
\left(\frac{A_{1}}{\xi}\right)^{\theta} & \ldots & 0 \\
\vdots & & \vdots \\
0 & \ldots & \left(\frac{A_{N}}{\xi}\right)^{\theta}
\end{array}\right]\left[\begin{array}{ccc}
\omega_{11} \tau_{11}^{-\theta} \beta_{1} & \ldots & \omega_{N 1} \tau_{N 1}^{-\theta} \beta_{N} \\
\vdots & & \vdots \\
\omega_{1 N} \tau_{1 N}^{-\theta} \beta_{1} & \ldots & \omega_{N N} \tau_{N N}^{-\theta} \beta_{N}
\end{array}\right]\right)^{-1} \text {. } \\
& {\left[\begin{array}{ccc}
\omega_{11} \tau_{11}^{-\theta}\left(1-\beta_{1}\right) & \ldots & \omega_{N 1} \tau_{N 1}^{-\theta}\left(1-\beta_{N}\right) \\
\vdots & & \vdots \\
\omega_{1 N} \tau_{1 N}^{-\theta}\left(1-\beta_{1}\right) & \ldots & \omega_{N N} \tau_{N N}^{-\theta}\left(1-\beta_{N}\right)
\end{array}\right]}
\end{aligned}
$$

\footnotetext{
${ }^{31}$ Like Eaton and Kortum (2002), we impose the triangular inequality $\tau_{n^{\prime} n} \leq \tau_{n^{\prime} n^{\prime \prime}} \tau_{n^{\prime \prime} n}$ : direct transportation from original exporter to final importer is always the cheapest option.

${ }^{32}$ Specifically, $\xi \equiv\left[\Gamma\left(\frac{\theta+1-\sigma}{\theta}\right)\right]^{\frac{1}{1-\sigma}}$, where $\Gamma(\cdot)$ is the gamma function. Note that $\sigma<1+\theta$ is required for this to exist. See Eaton and Kortum (2002).
} 
The Eaton-Kortum model outlined here thus yields the same functional form for the consumption price index as the Armington model described in Section 2, up to the value of the constant $\xi$.

It is easy to show that the two models have the same predictions for value-added trade patterns as long as $\left\{\gamma_{n^{\prime} n}\right\}_{n^{\prime}, n}$ coincide in both. ${ }^{33}$ In other words, a set of parameter values $\left\{A_{n}, \omega_{n^{\prime} n}, \tau_{n^{\prime}, n}, \beta_{n}\right\}$ for this Eaton-Kortum model calibrated to obtain the same set $\left\{\gamma_{n^{\prime} n}\right\}_{n^{\prime}, n}$ obtained from our Armington model, yields the same equilibrium outcomes $f_{n}$ and $v_{n^{\prime} n} .{ }^{34}$

\section{A.1.3 Gravity Equation}

Sales by country $n^{\prime}$ to country $n$ are $X_{n^{\prime} n}=\omega_{n^{\prime} n}\left(\tau_{n^{\prime} n} b_{n^{\prime}}\right)^{-\theta} S_{n} / \Phi_{n}$, where $S_{n}$ denotes total spending by country $n$. Total sales by country $n^{\prime}$ are

$$
\sum_{n=1}^{N} X_{n^{\prime} n}=\sum_{n=1}^{N} \frac{\omega_{n^{\prime} n}\left(\tau_{n^{\prime} n} b_{n^{\prime}}\right)^{-\theta}}{\Phi_{n}} S_{n}=\omega_{n^{\prime} n} b_{n^{\prime}}^{-\theta} \Lambda_{n^{\prime}}^{-\theta}
$$

where $\Lambda_{n^{\prime}}^{-\theta} \equiv \sum_{n} \tau_{n^{\prime} n}^{-\theta} S_{n} / \Phi_{n}$. Following Eaton and Kortum (2002) we obtain the gravity equation:

$$
X_{n^{\prime} n}=\left(\frac{\xi}{A_{n}}\right)^{\theta} \frac{\left(\frac{\tau_{n^{\prime} n}}{P_{n}}\right)^{-\theta} S_{n}}{\sum_{n^{\prime \prime}=1}^{N} \frac{\tau_{n^{\prime} n^{\prime \prime}}^{-\theta}}{\Phi_{n^{\prime \prime}}} S_{n^{\prime \prime}}} \sum_{n=1}^{N} X_{n^{\prime} n}
$$

Similarly,

$$
\frac{X_{n^{\prime} n} / S_{n}}{X_{n^{\prime} n^{\prime}} / S_{n^{\prime}}}=\left(\frac{P_{n^{\prime}} \tau_{n^{\prime} n}}{P_{n}}\right)^{-\theta},
$$

where the left-hand side of this equation is the "normalised import share" of country $n$ vis-à-vis country $n^{\prime}$. It is apparent that we can think of $\theta$ as the (gross) trade elasticity, as it controls how a change in the bilateral trade cost $\tau_{n^{\prime} n}$ affects bilateral trade between countries $n^{\prime}$ and $n$.

\section{A.2 Data Construction}

\section{A.2.1 Factor Endowment Data}

Countries' human and physical capital stocks are calculated from data provided in the Penn World Tables (PWT, edition 9.0) and Barro and Lee (2013).

The stock of human capital in country $n$ for any given year $\left(h_{n} L_{n}\right)$ is computed by multiplying the size of workforce $\left(L_{n}\right)$, reported directly in PWT, with a "quality

\footnotetext{
${ }^{33}$ One can see this by applying Shephard's Lemma to $P_{n}$ and comparing the resulting marketclearing conditions.

${ }^{34}$ The parameter restrictions $\gamma_{n^{\prime} n} \geq 0$ and $\sum_{n^{\prime}} \gamma_{n^{\prime} n}=1$ made in Sections 2.1 and 3.3 imply a number of restrictions on $\omega_{n^{\prime} n}, \tau_{n^{\prime} n}$ and $\beta_{n^{\prime}}$. It is easy to show, for example, that $\sum_{n^{\prime}} \gamma_{n^{\prime} n}=1$ implies $\sum_{n^{\prime}} \omega_{n^{\prime} n} B_{n^{\prime}} \tau_{n^{\prime} n}^{-\theta}=1$ for all $n$, where $B_{n} \equiv\left(1-\beta_{n}\right)+\beta_{n}\left(A_{n} / \xi\right)^{\theta}$.
} 
adjustment" $\left(h_{n}\right)$ based on the average number of years of schooling in the part of country n's population aged 15 or above (from Barro and Lee, 2013). The "quality adjustment" takes a piecewise linear form reflecting qualitative and quantitative evidence on the returns to education from Mincer regressions (for details, see Hall and Jones, 1999; Caselli, 2005). ${ }^{35}$

The size of the capital stock in country $n$ is obtained by cumulating PPP-adjusted annual aggregate investment data $\left(I_{n t}\right)$ from PWT using the perpetual inventory method:

$$
K_{n t}=I_{n t}+(1-\delta) K_{n t-1}
$$

Following Caselli (2005), we set $\delta=.06$. In our only departure from his methodology, we impose that the capital stock in the first year in which investment data is available ("year 0") is given by $K_{n 0}=2.6 \times Y_{n 0}$. The choice of initial capital stock is immaterial for countries with a long time series of real investment data. However, Inklaar and Timmer (2013) argue that $K_{n 0}=2.6 \times Y_{n 0}$ leads to superior results for transition economies, with a limited - and volatile - investment time series. Since our sample contains a number of transition economies which match this description, we adopt the convention proposed by Inklaar and Timmer (2013).

\section{A.2.2 International Value-Added Linkages}

Our source for information on international value-added linkages is the World Input Output Database (WIOD, see Timmer et al., 2015). The WIOD contains annual global input-output tables for 40 countries (and the "rest of the world") in the period 1995-2011. A typical cell represents the current dollar value of expenditure by use category $s$ in country $n$ on use category $s^{\prime}$ in country $n^{\prime}$. There are 40 use categories in total -35 industries, and 5 final sectors. The following manipulation of this data is based on Johnson and Noguera (2012) and Timmer et al. (2013).

For a given year, define $\mathbf{q}$ as an $(S N \times 1)$ vector which stacks the dollar values of output in each country-sector, and e as an $(S N \times 1)$ vector which stacks the dollar values of final expenditure on each country-sector. Then the well known inputoutput identity states that $\mathbf{q}=\mathbf{B e}$, where $\mathbf{B}$ is an $(S N \times S N)$ matrix known as the "Leontief inverse" (Leontief, 1936) whose typical element gives the production value of category $s^{\prime}$ in country $n^{\prime}$ needed to produce one unit of final output in category $s$ of country $n$.

Defining $\mathbf{R}$ as an $(S N \times S N)$ diagonal matrix whose typical diagonal element is the ratio of value added to output in sector $s$ of country $n, \mathbf{R B e}$ is then an $(S N \times 1)$ vector which stacks the dollar values of value added generated in each country-sector.

\footnotetext{
${ }^{35}$ Barro and Lee (2013) report average years of schooling quinquennially for the period 1950-2010. Since average schooling received changes very slowly over time in all countries, values for years between these quinquennial observations can reasonably be obtained by interpolation.
} 
All information required to construct $\mathbf{q}, \mathbf{B}$, e and $\mathbf{R}$ can be read off the WIOD tables, and we can now trace the use of value added generated by each country-sector to final demand in every country sector through appropriate decomposition of RBe. In particular,

$$
\mathbf{R B e}=\mathbf{R B}\left(\begin{array}{c}
E_{11} \\
\vdots \\
\vdots \\
\vdots \\
0
\end{array}\right)+. .+\mathbf{R B}\left(\begin{array}{c}
0 \\
\vdots \\
E_{s n} \\
\vdots \\
0
\end{array}\right)+\ldots+\mathbf{R B}\left(\begin{array}{c}
0 \\
\vdots \\
\vdots \\
\vdots \\
E_{S N}
\end{array}\right)
$$

where $E_{s n}$ denotes total final expenditure on category $s$ from country $n$. The summation component

$$
\mathbf{R B}\left(\begin{array}{c}
0 \\
\vdots \\
E_{s n} \\
\vdots \\
0
\end{array}\right)=\left(\begin{array}{c}
B_{11 s n} \\
\vdots \\
B_{s^{\prime} n^{\prime} s n} \\
\vdots \\
B_{S N s n}
\end{array}\right)
$$

now represents a $(S N \times 1)$ vector whose typical element reports the value added from category $s^{\prime}$ in country $n^{\prime}$ used in providing final use of category $s$ from country $n$. It follows that $\sum_{s^{\prime}} B_{s^{\prime} n^{\prime} s n} / E_{s n}$ represents the share of value added from country $n^{\prime}$ used in providing final output of category $s$ from country $n$.

By summing over the expenditure of all 5 final sectors in country $n$ on category $s$ from $n^{\prime}$, we obtain the share of country- $n$ expenditure on that category, denoted $E_{s n^{\prime} n} / E_{n}$. The final use by country $n$ of value added from country $n^{\prime}$ is then $v_{n^{\prime} n}=$ $\sum_{s} \sum_{n^{\prime \prime}}\left(\sum_{s^{\prime}} B_{s^{\prime} n^{\prime} s n^{\prime \prime}} / E_{s n^{\prime \prime}}\right) \times\left(E_{s n^{\prime \prime} n} / E_{n}\right) .{ }^{36}$ The matrix $\left\{v_{n^{\prime} n}\right\}_{n^{\prime}, n}$ represents our measure of international value-added linkages.

\section{A.2.3 Robustness}

In assembling our factor-endowment data, we closely follow Caselli (2005) to facilitate comparison of our results with his. Recent editions of PWT (starting with 8.0) provide "ready-made" human and physical capital stocks which were constructed using more up-to-date data and methods. In PWT 9.0, the biggest innovation in calculating human capital stocks vis-à-vis Caselli (2005) is the use of Cohen and Leker (2014) as a source of data on educational attainment in addition to Barro and Lee (2013). The biggest innovation in calculating physical capital stocks is the disaggregation of

\footnotetext{
${ }^{36}$ Note that, unlike Johnson and Noguera (2012), we are not pre-occupied with the value-added content of exports. Instead, like Timmer et al. (2013), we trace countries' value added contributions to the output of different final goods. However, we take their analysis of the data one step further by then attributing these final-good outputs to final expenditure in different countries.
} 
investment into up to six different asset classes with different depreciation rates. More detailed information can be found in Inklaar and Timmer $(2013,2016)$.

[Insert Table 10 here]

Table 10 compares success and ignorance statistics without and with the use of information on value-added linkages (alternatively imposing $\theta \rightarrow 0$ or $\theta=4$ ), for different factor-endowment datasets. The top panel uses data for the year 1996, the bottom panel data from 2006. In each panel, the first row reproduces the findings discussed in Section 3. Subsequent rows use different data-construction methods for the factor-endowment data and/or different editions of the PWT. In the "Data Construction" category, "Caselli (2005)" refers to the method for assembling factor data described in A.2.1, while "PWT" refers to the ready-made factor data available from the respective edition of PWT. The table serves to demonstrate that our findings are remarkably robust across these alternatives.

\section{A.3 Output-Side Real GDP}

\section{A.3.1 Import and Export Price Indices}

From the expenditure minimisation of the representative consumer in country $n$, we can write country- $n$ nominal GDP as

$$
\begin{aligned}
r_{n} K_{n}+w_{n} L_{n} & =P_{n} C_{n}+\sum_{n^{\prime} \neq n} p_{n n^{\prime}} c_{n n^{\prime}}-\sum_{n^{\prime} \neq n} p_{n^{\prime} n} c_{n^{\prime} n}= \\
& =P_{n} C_{n}+P_{n}^{x} C_{n}^{x}-P_{n}^{m} C_{n}^{m},
\end{aligned}
$$

where

$$
C_{n}^{m}=A_{n}\left(\sum_{n^{\prime} \neq n} \omega_{n^{\prime} n}^{\frac{1}{\sigma}} c_{n^{\prime} n}^{\frac{\sigma-1}{\sigma}}\right)^{\frac{\sigma}{\sigma-1}}, \quad C_{n}^{x}=\frac{A_{n} Z_{n} K_{n}^{\alpha} H_{n}^{1-\alpha}}{\omega_{n n}^{\frac{1}{1-\sigma}} \tau_{n n}}-A_{n} c_{n n}
$$

respectively denote aggregate import consumption, and aggregate domestic-good consumption forgone due to exports; and

$$
P_{n}^{m}=\frac{1}{A_{n}}\left(\sum_{n^{\prime} \neq n} \omega_{n^{\prime} n} p_{n^{\prime} n}^{1-\sigma}\right)^{\frac{1}{1-\sigma}}, \quad P_{n}^{x}=\frac{1}{A_{n}} \omega_{n n}^{\frac{1}{1-\sigma}} p_{n n}
$$

respectively denote the corresponding domestic import and export price indices.

\section{A.3.2 Revenue Function}

We can now define the revenue function for country $n$ as

$$
R_{n}\left(P_{n}, P_{n}^{x}, P_{n}^{m} ; K_{n}, H_{n}\right) \equiv
$$


$\equiv \max _{C_{n}, C_{n}^{m}, C_{n}^{x}}\left\{P_{n} C_{n}+P_{n}^{x} C_{n}^{x}-P_{n}^{m} C_{n}^{m} \mid\left(\frac{C_{n}^{m}}{C_{n}}\right)^{\frac{\theta}{1+\theta}}+\left(\frac{A_{n} K_{n}^{\alpha} H_{n}^{1-\alpha}}{\gamma_{n n}^{-\frac{1}{\theta}} C_{n}}-\frac{C_{n}^{x}}{C_{n}}\right)^{\frac{\theta}{1+\theta}}=1\right\}$,

where $\theta \equiv \sigma-1$, and $\gamma_{n^{\prime} n} \equiv \omega_{n^{\prime} n}\left(Z_{n^{\prime}} / \tau_{n^{\prime} n}\right)^{\theta}$.

\section{A.3.3 Output-Side Real GDP}

Feenstra et al. (2015) define the "output-side" real GDP of country $n\left(C G D P_{n}^{o}\right)$ as the revenue function of country $n$ evaluated at some vector of reference prices $\left(\Pi, \Pi^{x}, \Pi^{m}\right)$. Formally,

$$
C G D P_{n}^{o} \equiv R_{n}\left(\Pi, \Pi^{x}, \Pi^{m} ; K_{n}, H_{n}\right)=\Pi^{x} \gamma_{n n}^{\frac{1}{\theta}} A_{n} K_{n}^{\alpha} H_{n}^{1-\alpha} .
$$

Therefore, $\gamma_{n n}^{\frac{1}{\theta}} A_{n} K_{n}^{\alpha} H_{n}^{1-\alpha}$ equals the "output-side" real GDP of country $n$ up to the value of a constant (which will reflect the normalisation imposed on the set of reference prices). 